\title{
DNA methylation and survival differences associated with the type of IDH mutation in 1p/19q non- codeleted astrocytomas
}

Survival associated with IDH mutation-type

C Mircea S Tesileanu ${ }^{1}$, Wies R Vallentgoed ${ }^{1}$, Marc Sanson², Walter Taal ${ }^{1}$, Paul M Clement ${ }^{3}$, Wolfgang Wick ${ }^{4}$, Alba Ariela Brandes ${ }^{5}$, Jean Francais Baurain ${ }^{6}$, Olivier L Chinot ${ }^{7}$, Helen Wheeler ${ }^{8}$, Sanjeev Gill ${ }^{9}$, Matthew Griffin ${ }^{10}$, Leland Rogers ${ }^{11}$, Roberta Rudà ${ }^{12}$, Michael Weller ${ }^{13}$, Catherine McBain ${ }^{14}$, Jaap Reijneveld ${ }^{15}$, Roelien $\mathrm{H}$ Enting ${ }^{16}$, Francesca Caparrotti ${ }^{17}$, Thierry Lesimple ${ }^{18}$, Susan Clenton ${ }^{19}$, Anja Gijtenbeek $^{20}$, Elisabeth Lim ${ }^{21}$, Filip de Vos ${ }^{22}$, Paul J Mulholland ${ }^{23}$, Martin J B Taphoorn ${ }^{24}$, Iris de Heer ${ }^{1}$, Youri Hoogstrate ${ }^{1}$, Maurice de Wit ${ }^{1}$, Lorenzo Boggiani ${ }^{1}$, Sanne Venneker ${ }^{25}$, Jan Oosting ${ }^{25}$, Judith VMG Bovée $^{25}$, Sara Erridge ${ }^{26}$, Michael A Vogelbaum ${ }^{27}$, Anna K Nowak ${ }^{28,29,30}$, Warren P Mason ${ }^{31}$, Johan M Kros $^{32}$, Pieter Wesseling ${ }^{33}$, Ken Aldape ${ }^{34}$, Robert B Jenkins ${ }^{35}$, Hendrikus J Dubbink ${ }^{32}$, Brigitta Baumert $^{36,37}$, Vassilis Golfinopoulos ${ }^{38}$, Thierry Gorlia ${ }^{38}$, Martin van den Bent ${ }^{1}$ and Pim J French ${ }^{1}$

${ }^{1}$ Dept Neurology, Brain Tumor Center at Erasmus MC Cancer Institute Rotterdam, the Netherlands ${ }^{2}$ Sorbonne Universités UPMC Univ Paris 06, Inserm, CNRS, APHP, Institut du cerveau et de la moelle (ICM)- Hôpital Pitié-salpêtrière, Boulevard de I'hôpital, F-75013, Paris, France

${ }^{3}$ Department of Oncology, KU Leuven and Department of General Medical Oncology, UZ Leuven, Belgium

${ }^{4}$ Neurologische Klinik und Nationales Zentrum für Tumorerkrankungen Universitätsklinik, Heidelberg, Germany

${ }^{5}$ Medical Oncology Department, AUSL-IRCCS Scienze Neurologiche, Bologna Italy

${ }^{6}$ Medical Oncology Department, King Albert II Cancer Institute, Cliniques universitaires Saint-Luc, Université Catholique de Louvain, Bruxelles, Belgium

${ }^{7}$ Aix-Marseille University, AP-HM, Neuro-Oncology division, Marseille, France

${ }^{8}$ Northern Sydney Cancer Centre, St Leonards, NSW 2065 Australia: University of Sydney

${ }^{9}$ Dept Medical Oncology, Alfred Hospital, Melbourne, Australia

${ }^{10}$ Department of Clinical Oncology, Nottingham University Hospitals NHS Trust, Nottingham, UK

${ }^{11}$ Department of Radiation Oncology, Barrow Neurological Institute, Phoenix AZ USA

${ }^{12}$ Department of Neuro-Oncology, City of Health and Science Hospital and University of Turin, Italy

${ }^{13}$ Department of Neurology and Brain Tumor Center, University Hospital and University of Zurich, Zurich, Switzerland

${ }^{14}$ Department of Clinical Oncology, The Christie NHS FT, Manchester, UK

${ }^{15}$ Brain Tumor Center Amsterdam \& Department of Neurology, Amsterdam University Medical Center

${ }^{16}$ Department of Neurology, UMCG, University of Groningen, Groningen, the Netherlands

${ }^{17}$ Department of Radiation Oncology, University Hospital of Geneva, Geneva, Switzerland

${ }^{18}$ Department of Clinical Oncology, Comprehensive Cancer Center Eugène Marquis, Rennes, France

${ }^{19}$ Weston Park Hospital, Sheffield, UK

${ }^{20}$ Department of Neurology, Radboud University Medical Centre, Nijmegen, The Netherlands

${ }^{21}$ Department of Clinical Oncology, PLYMOUTH HOSPITALS NHS TRUST

${ }^{22}$ Department of Medical Oncology, UMC Utrecht Cancer Center, Utrecht, the Netherlands 
${ }^{23}$ University College Hospital, London, UK

${ }^{24} \mathrm{MC}$ Haaglanden, Den Haag, Netherlands

${ }^{25}$ Department of Pathology, Leiden University Medical Center, Leiden, The Netherlands

${ }^{26}$ Edinburgh Centre for Neuro-Oncology, Western General Hospital, University of Edinburgh, Edinburg, UK

${ }^{27}$ Department of NeuroOncology, Moffitt Cancer Center, Tampa, Florida, USA

${ }^{28}$ School of Medicine and Pharmacology, University of Western Australia, 35 Stirling, Highway Crawley WA 6009 Australia

${ }^{29}$ CoOperative Group for NeuroOncology, University of Sydney, Camperdown NSW, Australia

${ }^{30}$ Department of Medical Oncology, Sir Charles Gairdner Hospital, Hospital Avenue, Nedlands WA 6009

Australia

${ }^{31}$ Princess Margaret Cancer Centre, University of Toronto, Toronto, Canada

${ }^{32}$ Department of Pathology, Erasmus University Medical Center, Rotterdam, the Netherlands

${ }^{33}$ Department of Pathology, VU University Medical Center, Amsterdam, The Netherlands

${ }^{34}$ Princess Margaret Cancer Centre, University of Toronto

${ }^{35}$ Department of Laboratory Medicine and Pathology, Mayo Clinic, Rochester MN, USA

${ }^{36}$ Dept. Radiation-Oncology (MAASTRO), Maastricht University Medical Center (MUMC) and GROW (School for Oncology), Maastricht, Netherlands;

${ }^{37}$ Institute of Radiation-Onology, Chur, Switzerland

${ }^{38}$ EORCT HQ, Brussels, Belgium 
Single sentence summary: Astrocytoma patients with tumours harbouring IDH mutations other than p.R132H have increased DNA methylation levels and longer survival

\section{Abstract}

Somatic mutations in the isocitrate dehydrogenase genes $I D H 1$ and $I D H 2$ occur at high frequency in several tumour types. Even though these mutations are confined to distinct hotspots, we show that gliomas are the only tumour type with an exceptionally high percentage of $\mathrm{IDH} 1^{\mathrm{R} 132 \mathrm{H}}$ mutations. This high prevalence is important as $\mathrm{IDH}^{\mathrm{R} 132 \mathrm{H}}$ is presumed to be relatively poor at producing $\mathrm{D}-2$ hydroxyglutarate (D-2HG) whereas high concentrations of this oncometabolite are required to inhibit TET2 DNA demethylating enzymes. Indeed, patients harbouring $\mathrm{IDH} 1^{\mathrm{R} 132 \mathrm{H}}$ mutated tumours have lower levels of genome-wide DNA-methylation, and an associated increased gene expression, compared to tumours with other IDH1/2 mutations ("non-R132H mutations"). This reduced methylation is seen in multiple tumour types and thus appears independent of site of origin. For $1 p / 19 q$ non-codeleted glioma patients, we show that this difference is clinically relevant: in samples of the randomised phase III CATNON trial, patients harbouring non-R132H mutated tumours have better outcome ( $\mathrm{HR} 0.41,95 \% \mathrm{Cl}[0.24,0.71], \mathrm{p}=0.0013$ ). Non-R132H mutated tumours also had a significantly lower proportion of tumours assigned to prognostically poor DNA-methylation classes $(p<0.001)$. IDH mutation-type was independent in a multivariable model containing known clinical and molecular prognostic factors. To confirm these observations, we validated the prognostic effect of IDH mutation type on a large independent dataset. The observation that non-R132H mutated $1 \mathrm{p} / 19 \mathrm{q}$ noncodeleted gliomas have a more favourable prognosis than their $\mathrm{IDH} 1^{\mathrm{R} 132 \mathrm{H}}$ mutated counterpart is clinically relevant and should be taken into account for patient prognostication.

\section{Keywords}

Astrocytoma; D-2-hydroxyglutarate; oligodendroglioma; acute myeloid leukemia; chondrosarcoma; genome wide DNA methylation; gene expression; survival; IDH1; IDH2; p.R132H 


\section{Introduction}

Somatic mutations in the isocitrate dehydrogenase genes $I D H 1$ and $I D H 2$ occur at high frequency in various tumour types including gliomas (primary malignant central nervous system tumours), intrahepatic cholangiocarcinomas (bile duct tumours), enchondromas and chondrosarcomas (bone tumours), sinonasal undifferentiated carcinomas and leukemias ${ }^{1,2}$. More sporadic but similar mutations have been found in a wide variety of other tumour types including melanoma, prostate and pancreatic cancer ${ }^{3}$. IDH1/2 mutations are causal for the disease and tumours often remain dependent on the mutation for growth ${ }^{4,5}$. The importance of the mutation is confirmed by the activity of IDHinhibitors: inhibiting the mutant activity of either $I D H 1$ or $I D H 2$ shows anti-tumour activity in relapsed/refractory $I D H 1 / 2$ mutated acute myeloid leukemia ${ }^{6,7}$ and cholangiocarcinoma patients ${ }^{8}$. The objective response rates in these trials are in the order of $40 \%$, though patients eventually relapse. In gliomas however, mutant $I D H 1 / 2$ inhibitors have thus far not shown a survival benefit, but further studies on early-stage tumours are ongoing ${ }^{9}$.

The IDH1/2 mutations are confined to defined hotspots within the genes that affect either arginine 132 (R132) in IDH1 or the arginines R172 or R140 in IDH2. These mutations change the activity of the wild-type (wt) protein from an enzyme that produces alpha-ketoglutarate (aKG) to an enzyme that produces $\mathrm{D}-2$ hydroxyglutarate $(\mathrm{D}-2 \mathrm{HG})^{1,10}$. D-2HG in its turn is a main effector in oncogenesis e.g. by inhibiting aKG-dependent dioxygenases, which keeps cells in an undifferentiated state ${ }^{11,12}$. Although IDH1/2 mutations are confined to these three hotspots, several reports have shown that the IDHmutation spectrum differs per tumour type ${ }^{1,13-15}$. This difference is interesting as other groups have shown that mutations differ in their ability to produce $\mathrm{D}-2 \mathrm{HG}^{16,17}$. IDH1 ${ }^{\mathrm{R} 132 \mathrm{H}}$, the IDH1/2 mutation with relatively low $\mathrm{D}-2 \mathrm{HG}$ production capacity, is the most common mutation in gliomas; other mutations such as IDH1 $1^{\mathrm{R} 132 \mathrm{C}}$ have 10 -fold lower $K_{\mathrm{M}}$ and have higher enzymatic efficiency ${ }^{16,17}$. The differential $D$ 2HG production capacity is supported by observations from cell lines and clinical samples where tumours harbouring the IDH1 ${ }^{\mathrm{R} 132 \mathrm{H}}$ mutation have lower D-2HG levels compared to those with other IDH mutations ${ }^{16,18,19}$. This difference may have biological implications as not all aKG-dependent enzymes are equally well inhibited by D-2HG ${ }^{20,21}$.

Here, we have used data from six large and independent DNA methylation datasets (the randomised phase III CATNON clinical trial on anaplastic 1p/19q non-codeleted gliomas ${ }^{22}$, the TCGA-LGG cohort ${ }^{23}$, samples included in the TAVAREC randomised phase 2 clinical trial on $1 p / 19 q$ non-codeleted gliomas ${ }^{24}$, a large cohort of acute myeloid leukemias $(\mathrm{AML})^{25}$ and a cohort of chondrosarcomas (Venneker et al, accepted for publication)) derived from four different tumour types, to examine the molecular effects of different types of $I D H 1 / 2$ mutations. We report that tumours harbouring $I D H 1^{\mathrm{R} 132 \mathrm{H}}$ mutations, regardless of tumour type, have lower genome-wide DNA methylation levels compared to those harbouring other ('non-R132H') IDH1/2 hotspot mutations. For $1 p / 19 q$ non-codeleted glioma patients, we show this difference has clinical relevance as patients harbouring such non-R132H mutated tumours have improved survival. Our data support the notion that increased genome-wide DNA methylation levels are associated with improved outcome in this tumour type and indicate that the type of $I D H 1 / 2$ mutation should be taken into account for prognostication of $1 p / 19 q$ noncodeleted glioma patients. 


\section{Methods}

Datasets: The COSMIC database (assessed 27 December 2019) was screened for hotspot IDH1 (R132) and IDH2 (R172 and R140) mutations. Mutations were stratified by tumour type; tumours with low prevalence of mutations were concatenated ('other tumours': prostate $n=11$, pancreas $n=6$, skin $n=32$, large intestine $n=1$, soft tissue $n=22$, endometrium $n=1$, breast $n=9$, urinary tract $n=2$, liver $n=7$, stomach $n=1$, upper aerodigestive tract $n=35$, salivary gland $n=1$, thyroid $n=1$ ). CATNON clinical data ${ }^{22}$ and IDH1/2 mutation and DNA methylation data (Tesileanu, submitted) were reported previously. TCGA glioma data (DNA methylation and RNA-seq) ${ }^{23}$, MSK-IMPACT data ${ }^{26}$ and AML data ${ }^{25}$ were downloaded from the TCGA data portal. Clinical data and mutation status for the chondrosarcoma data were reported previously (Venneker et al, accepted for publication). Clinical data from the TAVAREC trial were derived from ref ${ }^{24}$, and supplemented with DNA methylation data of 89 tumours. Most (80\%) TAVAREC samples were derived from the initial tumour. Processing of CATNON and TAVAREC DNA methylation data was performed as described (Tesileanu, submitted). For the CATNON, TCGA-astrocytoma and TAVAREC datasets, we included only IDH1/2 mutated samples from non 1p/19q-codeleted tumours. For IDH1/2 mutated MSK-IMPACT samples, the distinction between astrocytic and oligodendrocytic tumours was made by absence or presence of telomerase reverse transcriptase (TERT) promoter mutations ${ }^{27,28}$. In the Chinese Glioma Genome Atlas [CGGA] ${ }^{29}$, the exact IDH-mutation was not noted and therefore limited for the scope of this analysis. We used only the $1 p / 19 q$ codeleted tumours in this dataset with IDH2 mutations being designated as "non-R132H" mutations and all IDH1 mutations as "R132H". In oligodendrogliomas, IDH1 mutations virtually always

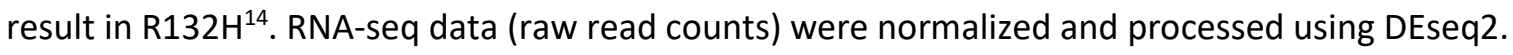

Statistical analysis: Survival curves were created using the Kaplan-Meier method. The log-rank test was used to determine survival differences. A Wilcoxon rank test on beta values (i.e. the intensity of the methylated probe/sum of methylated and unmethylated probe intensity) was used to identify differentially methylated probes in CATNON and TCGA-astrocytoma datasets. To increase power in the smaller sized datasets, we performed an F-test on M-values (i.e. the log2 ratio of the methylated/unmethylated probe intensities) to identify differentially methylated $\mathrm{CpGs}$ using the dmpFinder function in the Minfi Bioconductor package ${ }^{30}$. To further increase statistical power in the chondrosarcoma dataset (required as this dataset had few samples), we first made a selection of the most variable probes (i.e. those with a standard deviation $>2 ; \sim 5 \%$ of the total number of probes) followed by an F-test on the M-values. In all differential methylation analysis, $\mathrm{p}$-values were corrected for false discovery rate (adjusted P-value).

Differences in mutation frequencies were determined using a chi squared test. Pathway analysis was performed using Ingenuity pathway analysis (Qiagen, Venlo, the Netherlands). An association model was made with the Cox proportional hazards method and included, next to IDH1/2 mutation type, factors that are known to be related to outcome from literature such as sex, treatment with temozolomide, age at randomization, WHO performance score, MGMT promoter methylation status, use of corticosteroids at randomization, and DNA methylation profiling. All $p$ values below 0.05 were considered significant. Statistical analysis was performed using R version 3.6.3 and packages minfi, stats, rms, survival. 


\section{Results}

The IDH1 ${ }^{R 132 H}$ mutation predominates in gliomas

We screened the catalogue of somatic mutations in cancer (COSMIC) database ${ }^{31}$, extracted IDH1/2 hotspot mutation data (IDH1 $1^{\mathrm{R} 132}, \mathrm{IDH} 2^{\mathrm{R} 172}$ and IDH2 ${ }^{\mathrm{R} 140}$ ) and stratified them by tumour organ site. As expected, tumours with a high frequency of IDH1/2 mutations include central nervous system (CNS), biliary tract, bone, haematopoietic and lymphoid tumours (leukemias). Interestingly, even if there are only three mutational hotspots, there are marked differences in the distribution of mutations between tumour sites (figure 1). For example, the IDH1 ${ }^{\mathrm{R} 132 \mathrm{H}}$ mutation is by far the most predominant IDH mutation in CNS tumours ( $n=7265 / 8026,90.5 \%)$ whereas this mutation is present at much lower frequencies in bone $(n=49 / 361,13.6 \%)$, leukemic $(n=519 / 2995,17.3 \%)$ and other tumours $(n=14 / 129$, $10.9 \%)$, and thus far has never been identified in biliary tract tumours $(n=212)(p<0.001$, chi square test). In contrast, the mutation that results in $I D H 1^{R 132 C}$ is quite rare in gliomas $(223 / 8026,2.8 \%)$ but much more prevalent in all other tumour types: bone $(n=212 / 361,67.1 \%)$, leukemic $(n=493 / 2995$, $16.5 \%)$, biliary tract $(n=114 / 212,53.8 \%)$ and other tumours $(n=14 / 129,10.9 \%)$. This difference is despite the fact that the IDH1 $1^{\mathrm{R} 132 \mathrm{H}}$ and the $\mathrm{IDH} 1^{\mathrm{R} 132 \mathrm{C}}$ are both the result of a transition mutation $(\mathrm{G}>\mathrm{A}$ and $\mathrm{C}>\mathrm{T}$, respectively). In general, transition mutations are much more common than transversion mutations $^{32}$. There is also a major difference in the distribution of $I D H 2$ mutations which are very common in haematopoietic and lymphoid tumours but rare in all other tumour types. Mutations of the R140 in IDH2 are virtually exclusive to haematopoietic and lymphoid tumours.

\section{DNA methylation is lower in IDH1 ${ }^{R 132 H}$ mutant glioma}

Previous reports have shown that D-2HG is a weak inhibitor of TET2 enzymes as relatively high levels of D-2HG are required to inhibit the enzyme ${ }^{21,33}$. We therefore hypothesized that IDH mutations that are presumed to be poor in producing D-2HG (i.e. IDH1 ${ }^{\mathrm{R} 132 \mathrm{H}}$ ), produce levels of the oncometabolite that are insufficient to completely inhibit the aKG-dependent dioxygenase TET2. If so, based on the molecular function of TET2 enzymes in mediating the first step in DNA demethylation, IDH1 ${ }^{\mathrm{R} 132 \mathrm{H}}$ mutated tumours may have lower levels of DNA methylation than those harbouring other hotspot IDH mutations ("non-R132H" mutations).

To test this hypothesis, we used genome-wide DNA methylation data from CATNON trial samples and compared profiles of IDH1 ${ }^{\mathrm{R} 132 \mathrm{H}}$ mutated tumours ( $n=369$, presumed low D-2HG production) to those harbouring other "non-R132H" IDH1 and IDH2 hotspot mutations ( $\mathrm{H}=69$, presumed high D-2HG production). Our data shows that the overall level of DNA methylation was significantly lower in tumours harbouring $\mathrm{IDH} 1^{\mathrm{R} 132 \mathrm{H}}$ mutations compared to tumours harbouring non-R132H mutations. For example, there are 2461 probes showing a reduction in beta values $>0.2$ in IDH $1^{\mathrm{R} 132 \mathrm{H}}$ mutated tumours (at $p<0.01$ ) but there are no probes showing an increase $>0.2$. This is exemplified in the volcano plot where a strong skew towards increased DNA methylation in non-R132H mutated samples is observed (figure 2A). Probes showing the largest increase in DNA methylation were those that were partially methylated in $\mathrm{IDH} 1^{\mathrm{R} 132 \mathrm{H}}$ mutated tumours (i.e. probes with beta values between 0.25 and 0.75 ); there were few probes that became (partially) methylated from an unmethylated state (figure $2 \mathrm{~B}$ ).

Gliomas with higher levels of genome wide DNA methylation generally are associated with longer survival in adults ${ }^{23,34-36}$. Since non-R132H mutated gliomas have increased DNA methylation levels, we compared overall survival of patients with different IDH mutations. In patients included in the CATNON randomised phase III clinical trial, those harbouring tumours with non-R132H mutations indeed had 
longer overall survival compared to patients harbouring $\mathrm{IDH} 1^{\mathrm{R} 132 \mathrm{H}}$ mutated tumours ( figure $2 \mathrm{C}$ ). The hazard ratio for non-R132H mutations was $0.41,95 \% \mathrm{Cl}[0.24,0.71], \mathrm{p}=0.0013$.

DNA methylation profiling can also assign tumours to specific (prognostic) methylation subclasses. In line with the poorer survival, IDH1 $1^{\mathrm{R} 132 \mathrm{H}}$ mutated tumours also had a significantly higher proportion assigned to the prognostically poorer subclass A_IDH_HG ("IDH-mutant, high grade astrocytoma", $n=100 / 366$ v. 9/71, $p=0.036$, chi-squared test) using the subclasses as defined by Capper et al. ("CNSclassifier") $)^{37}$. They also have a higher proportion of G-CIMP low tumours (18/369 v. 0/62) and G-CIMPhigh tumours with risk to progression to G-CIMP low (111/335 v. 2/62) in the classifier as defined by the TCGA and de Souza et al. ("glioma classifier", $p<0.001$, chi-squared test, table 1) ${ }^{23,34}$.

A heatmap of the most differentially methylated CpGs of CATNON data ( $n=677$, selected on a beta value change $>0.25$ and false discovery corrected $p$ values $<10 \mathrm{e}-5$ ) shows a gradient from high to low methylation levels. As expected, the non-R132H mutated tumours cluster together at the highmethylation end of this spectrum. Interestingly, most of the tumours with less favourable molecular subtypes (A_IDH_HG, G-CIMP low, G-CIMP high with risk to progression) clustered together at the other, demethylated end (figure 2E). Although the clinical follow-up of CATNON patients is limited, the number of mortality events also tended to cluster at the demethylated end of the heatmap which suggests that there is a strong correlation between the level of methylation of these 677 probes and survival.

To determine whether the type of mutation is a prognostic factor independent of the DNA methylation subtypes, we stratified these subtypes by IDH1/2 mutation (IDH1 ${ }^{\mathrm{R} 132 \mathrm{H}} v$. non-R132H). Our data show that, even within the prognostic DNA methylation subtypes, patients harbouring non-R132H mutated tumours had a significantly longer survival compared to those harbouring IDH1 $1^{\mathrm{R} 132 \mathrm{H}}$-mutated tumours, regardless of the classifier used (figure 2D, supplementary figure 1 ). The type of IDH1/2 mutation was also an independent prognostic factor in a multivariable analysis that included all known factors associated with survival in this trial (treatment, age, corticosteroid use and sex, supplementary table 1). It remained significant when DNA methylation subclass was included in this analysis (table 1 , supplementary table 2). These data demonstrate that the type of IDH1/2 mutation is an independent factor associated with patient survival.

To confirm these observations, we performed a similar analysis on the IDH1/2 mutated, $1 p / 19 q$ noncodeleted glioma patients included in the TCGA dataset ${ }^{23}$. Similar to observed in the CATNON dataset, a striking increase in DNA methylation levels was seen in non-R132H mutated tumours compared to those harbouring a IDH1 ${ }^{\mathrm{R} 132 \mathrm{H}}$ mutation (figure $3 \mathrm{AB}$ ). Also similar was the observation that patients harbouring non- $\mathrm{R} 132 \mathrm{H}$ mutated tumours survived significantly longer; the HR of patients harbouring non-R132H mutated tumours $(n=37)$ versus IDH1 ${ }^{\mathrm{R} 132 \mathrm{H}}$-mutated tumours $(\mathrm{n}=177)$ was $0.20(95 \% \mathrm{Cl}$ $[0.047,0.837], p=0.028$ figure $3 C$ ). Finally, IDH1 ${ }^{R 132 H}$ mutated tumours also had a higher proportion of tumours assigned to the prognostically poorer G-CIMP low DNA methylation class (4/116 v. 0/27) and a higher number at risk of progression to G-CIMP low (29/111 v. 0/24, p=0.016).

DNA methylation generally shows a negative correlation with gene expression, especially when the methylated CpGs are located near the transcriptional start site ${ }^{38,39}$. We therefore examined whether the reduction in DNA methylation in IDH1 $1^{\mathrm{R} 132 \mathrm{H}}$ mutated tumours is associated with an increase in gene expression in the $1 p / 19 q$ non-codeleted gliomas present in the TCGA dataset. Indeed, of the genes differentially expressed between IDH mutation types (with $>2$ fold change in expression level at $p<0.01$ 
significance level) in astrocytomas, most $(157 / 183,86 \%)$ were upregulated in IDH1 ${ }^{\mathrm{R} 132 \mathrm{H}}$ mutated tumours (figure 3D, supplementary table 3). Pathway analysis using these 183 genes indicates that genes upregulated in $\mathrm{IDH} 1^{\mathrm{R} 132 \mathrm{H}}$ mutated tumours were involved in cellular movement, cell death and survival, cell-to-cell signalling and interaction and carbohydrate metabolism (supplementary figure 2).

We performed a second validation using $1 p / 19 q$ non-codeleted samples included in the randomised phase II TAVAREC clinical trial. Again, the vast majority of probes had lower DNA methylation levels in $I D H 1^{R 132 H}$ mutated tumours ( $n=83$ ) compared to non-R132H mutated tumours ( $n=11$, figure $4 A$ ) and the most differentially methylated probes were those partially methylated in $I D H 1^{\mathrm{R} 132 \mathrm{H}}$ mutated tumours (figure 4B). Moreover, there was a large degree of overlap in differential DNA methylation between CATNON and TAVAREC samples (figure 4C). In TAVAREC, there was no significant difference in survival between patients harbouring IDH1 ${ }^{\mathrm{R} 132 \mathrm{H}}$ and non-R132H mutated tumours (HR $1.21,95 \% \mathrm{Cl}$ $[0.60,2.45], \mathrm{P}=0.60)$. This however, may be related to the specific inclusion criteria of this trial: patients were included only when the tumour showed signs of malignant progression at the time of progression (i.e. contrast enhancement on the MRI scan). In this respect it is interesting to note that the percentage of non-R132H mutated tumours was almost two-fold lower in TAVAREC trial samples (13\%) compared to CATNON (19\%) and TCGA (20\%). Although this difference in frequency was not significant, these numbers are in line with the notion that non-R132H mutated tumours have lower frequencies of malignant progression. The small number of patients harbouring non-R132H mutated tumours ( $n=11$ ) may also mask potential survival differences. A heatmap of most differentially methylated probes shows that non-R132H-mutated tumours and tumours assigned to the prognostically poorer subclass A_IDH_HG clustered at opposites ends of this heatmap (figure 4D).

A forest plot of the combined CATNON, TCGA and TAVAREC survival data shows a summary estimate $\mathrm{HR}$ for non-R132H mutated tumours of 0.56 with $95 \% \mathrm{Cl}[0.37,0.85]$, association $\mathrm{p}=0.006$ (figure $4 \mathrm{E}$ ).

To test whether mutation-dependent DNA methylation differences were restricted to $1 p / 19 q$ noncodeleted gliomas, we analysed the genome-wide methylation profiles of i) IDH1/2 mutated, 1p/19q codeleted gliomas (TCGA) ii) acute myeloid leukemias (TCGA) and iii) chondrosarcomas. Although the sample sizes of these datasets were relatively small in all tumour types (1p/19q codeleted gliomas $n=135$ v. 14; acute myeloid leukemias $n=4$ v. $n=24$; chondrosarcomas $n=3 v . n=17$ for $I D H 1^{R 132 H}$ and non- $\mathrm{R} 132 \mathrm{H}$ mutated tumours respectively), there was less DNA methylation in IDH1 ${ }^{\mathrm{R} 132 \mathrm{H}} v$. non- $\mathrm{R} 132 \mathrm{H}$ mutation tumours (figure $5 \mathrm{~A}-\mathrm{C}$ ). These data demonstrate that the level of DNA methylation is lower in tumours harbouring IDH1/2 mutations with presumed low D-2HG production.

Gene expression analysis of $1 p / 19 q$ codeleted gliomas present in the TCGA dataset identified 148 differentially expressed genes (expression fold change $>1$ or $<-1$ and $p<0.01$ ). Similar to observed in astrocytic tumours, the majority of identified genes $(123 / 148,83 \%)$ were upregulated in $I D H 1^{R 132 H}$ mutated tumours (supplementary table 4). Moreover, there was a relatively large degree of concordance in differential expression between the two analyses (figure 5D) and sixteen genes were identified in both analyses.

The number of samples and events of the various datasets in patients with $1 p / 19 q$ codeleted gliomas was insufficient to determine mutation type dependent survival differences. For example, there were only 14 non-R132H mutated 1p/19q codeleted tumours in the TCGA dataset, with only 1 event noted (in the IDH1 ${ }^{\mathrm{R} 132 \mathrm{H}}$ mutated tumours there were 14 events in 135 patients). The HR for TCGA samples 
was 0.59 (95\% Cl $[0.077,4.595], p=0.62$, figure 5E). Also in the MSK-Impact ${ }^{26}$ and the Chinese Glioma Genome Atlas (CGGA) ${ }^{29}$ there were too few samples and events to determine survival benefit in patients harbouring non-R132H-mutated tumours. In these datasets, the events/number in non$\mathrm{R} 132 \mathrm{H}$ v. IDH1 ${ }^{\mathrm{R} 132 \mathrm{H}}$ mutated samples was $0 / 6$ v. $3 / 34$ and $0 / 5$ v. 3/31 in MSK impact, and CGGA datasets respectively. We were not able to determine survival differences in AML ( $n=12$ with 5 events v. $n=89,54$ events, HR 1.49, 95\% CI[0.59, 3.75], $p=0.39$, figure 5F). 


\section{Discussion}

Our data shows that IDH1/2mt gliomas are distinct when compared to other IDH1/2mt tumours in that they have a disproportionally high percentage of $\mathrm{IDH} 1^{\mathrm{R} 132 \mathrm{H}}$ mutations and raise the attractive clinical association between different rarer (codon 132) mutations and outcome. Patients harbouring IDH1 ${ }^{\mathrm{R} 132 \mathrm{H}}$ mutated tumours have lower levels of genome-wide DNA methylation, regardless of tumour type (1p/19q non-codeleted gliomas, 1p/19q codeleted gliomas, AML and chondrosarcomas). For $1 \mathrm{p} / 19 \mathrm{q}$ non-codeleted IDH1/2mt gliomas, this difference is clinically relevant as patients harbouring non- $\mathrm{R} 132 \mathrm{H}$ mutated tumours have improved outcome. Since IDH $1^{\mathrm{R} 132 \mathrm{H}}$ mutations are presumed to be relatively poor in D-2HG production, our data are in line with the observation that glioma patients with higher D-2HG levels have improved outcome ${ }^{40}$. Our data are also in line with data from a meeting abstract showing similar mutation-specific survival differences ${ }^{41}$

The observation that patients harbouring non-R132H mutated gliomas have longer survival is of importance for clinical practice as the specific IDH1/2 mutation could alter patient prognostication. In this respect diagnostic assays should be able to discriminate between the type of IDH-mutation present; non-R132H mutations comprise of up to $20 \%$ of all IDH-mutations in $1 \mathrm{p} / 19 \mathrm{q}$ non-codeleted gliomas. Moreover, the efficacy of treatment with alkylating agents, IDH1/2 inhibitors, or other novel treatments might vary per mutation type, and therefore may be taken into account as stratification factor in future clinical trials.

It has been reported that D-2HG is a relatively weak inhibitor of TET2. In fact, the IC50 value for TET2 inhibition ( $\sim 5 \mathrm{mM}$ ) is in the same range as the intratumoural D-2HG levels ${ }^{18,33,42,43}$. As TET2 mediates the first step in DNA demethylation, lower D-2HG levels may result in reduced inhibition of DNAdemethylation. Such lower D-2HG levels have been reported for IDH1 ${ }^{\mathrm{R} 132 \mathrm{H}}$ mutated tumours in some studies ${ }^{18,43,44}$ (but not in all ${ }^{42}$ ), though confounding factors such as tumour purity may influence these observations. In addition, the $K_{\mathrm{M}}$ for $\mathrm{D}-2 \mathrm{HG}$ production of the IDH1 ${ }^{\mathrm{R} 132 \mathrm{H}}$ mutation is higher than that of other IDH1 mutations (though the enzymatic efficiency may be similar for some mutations) ${ }^{17}$. Although we did not directly measure D-2HG levels, the partial inhibition of TET2, may explain the lower overall methylation in IDH1 ${ }^{\mathrm{R} 132 \mathrm{H}}$-mutated tumours.

The improved outcome of non- $\mathrm{R} 132 \mathrm{H}$ mutated astrocytomas may be explained by a reduced expression of genes that support tumour growth and/or induce treatment sensitivity caused by the increase in $\mathrm{CpG}$ methylation. Evidence supporting this hypothesis is the observation that many of the differentially expressed genes are involved in pathways associated with cancer. However, the improved outcome of non- $\mathrm{R} 132 \mathrm{H}$ mutated astrocytomas may also be related to the observation that $\mathrm{D}-2 \mathrm{HG}$ is toxic to cells, though only at high concentrations. For example, we have previously shown that exposure to D-2HG or expression of mutated IDH constructs reduced proliferation of cells, both in-vitro and in-vivo ${ }^{45}$. Later independent studies largely confirmed these observations and also conversely, reduction of D-2HG levels by mutant IDH inhibitors increased cell proliferation ${ }^{16,46-49}$. It should be noted however, that in some preclinical model systems a growth inhibitory effect of IDHinhibitors was observed ${ }^{50,51}$. Functional experiments should confirm this hypothesis. Alternatively, differences in genetic stress and related mutational signatures may also explain the differential distribution of mutations in $\mathrm{IDH}^{32,52}$. 
Limitations of this study include the relatively small sample size of several datasets, especially those with diagnosis other than the non-1p/19q codeleted gliomas. In addition, the absence of D-2HG level data limits the exploration of a direct correlation between $I D H 1 / 2$ mutation type and genome-wide DNA methylation.

In short, we described the effect of $I D H 1 / 2$ mutation type on patient outcome and the strong correlation between these specific mutations and genome-wide DNA methylation status. Our observation that non-R132H-mutated $1 \mathrm{p} / 19 \mathrm{q}$ non-codeleted gliomas have a more favourable prognosis than their IDH1 ${ }^{\mathrm{R} 132 \mathrm{H}}$ mutated counterpart is clinically relevant and should be taken into account for patient prognostication. 


\section{Acknowledgements}

The CATNON study was funded by Merck, Sharp and Dohme, and the Brain Tumor Group. The genomewide DNA methylation profiles study was funded by grant GN-000577 from The Brain Tumour Charity, grant 10685 from the Dutch Cancer Society, financial support from the Vereniging Heino 'Strijd van Salland', and grant CA170278 from the United States Department of Defence. The authors thank the European Organization for Research and Treatment of Cancer for permission to use the data from EORTC studies 26053/22054 (CATNON) and 26091 (TAVAREC) for this research.

\section{Author contributions}

Conceptualization: PJF

Methodology: CMT, YH, PJF

Validation: CMT

Investigation CMT, WRV, IdH, MdW, LB, PJF

Resources: MS, WT, PMC, WW, AAB, JFV, OLC, HW, SG, MG, LR, RR, MW, CMCB, JR, RHE, FC, TL, SC, AG, EL, FdV, PJM, MJBT, SV, JO, JVMGB, SE, MAV, AKN, WPM, JMK, PW, KA, RBJ, HJD, BB, VG, MvdB

Data curation CMT, TG, PJF

Writing-original draft: CMT, WRV, MvdB, PJF

Writing-review and editing: all authors

Visualization: CMT, PJF

Supervision: MvdB, PJF

\section{Competing interests}

MS reports research grants from Astra-Zeneca, travel grant from Abbvie, personal fees from Genenta, outside the submitted work, PM reports support to attend conferences from BMS and an award towards an investigator initiated study from BMS. BB reports a MERCK grant for the EORTC22033 IGG study. MAV has indirect equity interest and royalty rights from Infuseon Therapeutics, Inc. He has received honoraria from Tocagen, Cellinta, and Celgene. None of these interests overlap with the research presented in this manuscript. Wolfgang Wick receives trial funding from Apogenix, Boehringer Ingelheim, Pfizer and Roche to the institution. He serves on advisory boards for Agios, Bayer, MSD, Novartis, Roche with compensation paid to the institution. MJvdB reports grants from Dutch Cancer Foundation, grants from Brain Tumor Charity, grants from Strijd van Salland, grants from MSD formerly Schering Plough, during the conduct of the study; personal fees from Carthera, personal fees from Nerviano, personal fees from Bayer, personal fees from Celgene, personal fees from Agios, personal fees from Abbvie, personal fees from Karyopharm, personal fees from Boston Pharmaceuticals, personal fees from Genenta, outside the submitted work. AN received research funding from Astra Zeneca, and Douglas Pharmaceuticals, consultancies for Bayer, Roche, Boehringer Ingelheim, MSD, Douglas Pharmaceuticals, Pharmabcine, Atara biotherapeutics, Trizell and Seagen. MW has received research grants from Abbvie, Adastra, Merck, Sharp \& Dohme (MSD), Merck (EMD), Novocure and Quercis, and honoraria for lectures or advisory board participation or consulting from Abbvie, Adastra, Basilea, Bristol Meyer Squibb (BMS), Celgene, Medac, Merck, Sharp \& Dohme (MSD), Merck (EMD), Nerviano Medical Sciences, Novartis, Orbus, Philogen, Roche and Tocagen. FdV reports support from AbbVie, Bioclin Therapeutics, BMS, GSK, Novartis, Octimed Oncology and Vaximm, outside the submitted work. PC reports support from BMS, AbbVie, Merck Serono, MSD, Vifor Pharma, 
Daiichi Sankyo, Leo Pharma and Astra Zeneca, ouside the submitted work. PJF reports grants from Dutch Cancer Foundation, the Brain Tumor Charity, the Strijd van Salland, de Westlandse ride and Hersentumorfonds, outside submitted work. Other authors report no conflict of interest. 


\section{References}

1. Clark O, Yen K,Mellinghoff IK.Molecular Pathways: Isocitrate Dehydrogenase Mutations in Cancer. Clin Cancer Res. 2016; 22(8): 1837-1842

2. Mito JK, Bishop JA, Sadow PM, et al.Immunohistochemical Detection and Molecular Characterization of IDH-mutant Sinonasal Undifferentiated Carcinomas. Am J Surg Pathol. 2018; 42(8): 1067-1075

3. Zehir A, Benayed R, Shah RH, et al.Mutational landscape of metastatic cancer revealed from prospective clinical sequencing of 10,000 patients. Nature medicine. 2017; 23(6): 703-713

4. Hirata M, Sasaki M, Cairns RA, et al.Mutant IDH is sufficient to initiate enchondromatosis in mice. Proc Natl Acad Sci U S A. 2015; 112(9): 2829-2834

5. Sasaki M, Knobbe CB, Munger JC, et al.IDH1(R132H) mutation increases murine haematopoietic progenitors and alters epigenetics. Nature. 2012;

6. Stein EM, DiNardo CD, Pollyea DA, et al.Enasidenib in mutant IDH2 relapsed or refractory acute myeloid leukemia. Blood. 2017; 130(6): 722-731

7. DiNardo CD, Stein EM, de Botton S, et al.Durable Remissions with Ivosidenib in IDH1Mutated Relapsed or Refractory AML. N Engl J Med. 2018; 378(25): 2386-2398

8. Abou-Alfa GK, Macarulla T, Javle MM, et al.Ivosidenib in IDH1-mutant, chemotherapyrefractory cholangiocarcinoma (ClarIDHy): a multicentre, randomised, double-blind, placebocontrolled, phase 3 study. Lancet Oncol. 2020; 21(6): 796-807

9. Mellinghoff IK, Ellingson BM, Touat $\mathrm{M}$, et al.Ivosidenib in Isocitrate Dehydrogenase 1Mutated Advanced Glioma. J Clin Oncol. 2020; JCO1903327

10. Kloosterhof NK, Bralten LB, Dubbink HJ, French PJ,van den Bent MJ.Isocitrate dehydrogenase-1 mutations: a fundamentally new understanding of diffuse glioma? Lancet Oncol. 2011; 12(1): 83-91

11. Gagne LM, Boulay K, Topisirovic I, Huot ME,Mallette FA.Oncogenic Activities of IDH1/2 Mutations: From Epigenetics to Cellular Signaling. Trends Cell Biol. 2017; 27(10): 738-752

12. Losman JA,Kaelin WG, Jr. What a difference a hydroxyl makes: mutant IDH, (R)-2hydroxyglutarate, and cancer. Genes Dev. 2013; 27(8): 836-852

13. Pansuriya TC, van Eijk R, d'Adamo $P$, et al.Somatic mosaic IDH1 and IDH2 mutations are associated with enchondroma and spindle cell hemangioma in Ollier disease and Maffucci syndrome. Nat Genet. 2011; 43(12): 1256-1261

14. Gravendeel LA, Kloosterhof NK, Bralten LB, et al.Segregation of non-p.R132H mutations in IDH1 in distinct molecular subtypes of glioma. Hum Mutat. 2010; 31(3): E1186-1199

15. Farshidfar F, Zheng S, Gingras MC, et al.Integrative Genomic Analysis of Cholangiocarcinoma Identifies Distinct IDH-Mutant Molecular Profiles. Cell Rep. 2017; 18(11): 2780-2794

16. Pusch S, Schweizer L, Beck AC, et al.D-2-Hydroxyglutarate producing neo-enzymatic activity inversely correlates with frequency of the type of isocitrate dehydrogenase 1 mutations found in glioma. Acta Neuropathol Commun. 2014; 2(1): 19

17. Avellaneda Matteo D, Grunseth AJ, Gonzalez ER, et al.Molecular mechanisms of isocitrate dehydrogenase 1 (IDH1) mutations identified in tumors: The role of size and hydrophobicity at residue 132 on catalytic efficiency. J Biol Chem. 2017; 292(19): 7971-7983

18. Gross S, Cairns RA, Minden MD, et al.Cancer-associated metabolite 2-hydroxyglutarate accumulates in acute myelogenous leukemia with isocitrate dehydrogenase 1 and 2 mutations. The Journal of experimental medicine. 2010; 207(2): 339-344

19. Jin G, Reitman ZJ, Spasojevic I, et al.2-hydroxyglutarate production, but not dominant negative function, is conferred by glioma-derived NADP-dependent isocitrate dehydrogenase mutations. PLOS ONE. 2011; 6(2): e16812

20. Chowdhury R, Yeoh KK, Tian YM, et al.The oncometabolite 2-hydroxyglutarate inhibits histone lysine demethylases. EMBO reports. 2011; 12(5): 463-469

21. Xu W, Yang H, Liu Y, et al.Oncometabolite 2-Hydroxyglutarate Is a Competitive Inhibitor of alpha-Ketoglutarate-Dependent Dioxygenases. Cancer Cell. 2011; 19(1): 17-30 
22. van den Bent MJ, Baumert B, Erridge SC, et al.Interim results from the CATNON trial (EORTC study 26053-22054) of treatment with concurrent and adjuvant temozolomide for $1 p / 19 q$ non-co-deleted anaplastic glioma: a phase 3, randomised, open-label intergroup study. Lancet. 2017; 390(10103): 1645-1653

23. Ceccarelli M, Barthel FP, Malta TM, et al.Molecular Profiling Reveals Biologically Discrete Subsets and Pathways of Progression in Diffuse Glioma. Cell. 2016; 164(3): 550-563

24. van den Bent MJ, Klein M, Smits M, et al.Bevacizumab and temozolomide in patients with first recurrence of WHO grade II and III glioma, without 1p/19q co-deletion (TAVAREC): a randomised controlled phase 2 EORTC trial. Lancet Oncol. 2018; 19(9): 1170-1179

25. Tyner JW, Tognon CE, Bottomly D, et al.Functional genomic landscape of acute myeloid leukaemia. Nature. 2018; 562(7728): 526-531

26. Cheng DT, Mitchell TN, Zehir A, et al.Memorial Sloan Kettering-Integrated Mutation Profiling of Actionable Cancer Targets (MSK-IMPACT): A Hybridization Capture-Based NextGeneration Sequencing Clinical Assay for Solid Tumor Molecular Oncology. The Journal of molecular diagnostics : JMD. 2015; 17(3): 251-264

27. Suzuki H, Aoki K, Chiba K, et al.Mutational landscape and clonal architecture in grade II and III gliomas. Nat Genet. 2015;

28. Killela PJ, Reitman ZJ, Jiao Y, et al.TERT promoter mutations occur frequently in gliomas and a subset of tumors derived from cells with low rates of self-renewal. Proc Natl Acad Sci U S A. $2013 ; 110(15): 6021-6026$

29. $\mathrm{Hu} \mathrm{H}, \mathrm{Mu} \mathrm{Q}, \mathrm{Bao} Z$, et al.Mutational Landscape of Secondary Glioblastoma Guides METTargeted Trial in Brain Tumor. Cell. 2018; 175(6): 1665-1678 e1618

30. Aryee MJ, Jaffe AE, Corrada-Bravo $\mathrm{H}$, et al.Minfi: a flexible and comprehensive Bioconductor package for the analysis of Infinium DNA methylation microarrays. Bioinformatics. 2014; 30(10): 1363-1369

31. Forbes SA, Beare D, Boutselakis $\mathrm{H}$, et al.COSMIC: somatic cancer genetics at high-resolution. Nucleic Acids Res. 2017; 45(D1): D777-D783

32. Alexandrov LB, Kim J, Haradhvala NJ, et al.The repertoire of mutational signatures in human cancer. Nature. 2020; 578(7793): 94-101

33. Losman JA, Koivunen P,Kaelin WG, Jr.2-Oxoglutarate-dependent dioxygenases in cancer. Nat Rev Cancer. 2020;

34. de Souza CF, Sabedot TS, Malta TM, et al.A Distinct DNA Methylation Shift in a Subset of Glioma CpG Island Methylator Phenotypes during Tumor Recurrence. Cell Rep. 2018; 23(2): 637-651

35. Noushmehr H, Weisenberger DJ, Diefes K, et al.Identification of a $\mathrm{CpG}$ island methylator phenotype that defines a distinct subgroup of glioma. Cancer Cell. 2010; 17(5): 510-522

36. Kloosterhof NK, de Rooi JJ, Kros M, et al.Molecular subtypes of glioma identified by genomewide methylation profiling. Genes Chromosomes Cancer. 2013; 52(7): 665-674

37. Capper D, Jones DTW, Sill M, et al.DNA methylation-based classification of central nervous system tumours. Nature. 2018; 555(7697): 469-474

38. van den Bent MJ, Gravendeel LA, Gorlia T, et al.A hypermethylated phenotype is a better predictor of survival than MGMT methylation in anaplastic oligodendroglial brain tumors: a report from EORTC study 26951. Clin Cancer Res. 2011; 17(22): 7148-7155

39. Spainhour JC, Lim HS, Yi SV, Qiu P.Correlation Patterns Between DNA Methylation and Gene Expression in The Cancer Genome Atlas. Cancer Inform. 2019; 18(1176935119828776

40. Natsumeda $\mathrm{M}$, Igarashi $\mathrm{H}$, Nomura $\mathrm{T}$, et al.Accumulation of 2-hydroxyglutarate in gliomas correlates with survival: a study by 3.0-tesla magnetic resonance spectroscopy. Acta Neuropathol Commun. 2014; 2(158

41. Franceschi E, De Biase D, Pession A, et al.Survival outcomes in glioma patients with noncanonical IDH mutations: Beyond diagnostic improvements. J Clin Oncol. 2019; 37(15 (suppl)): 2028 
42. Choi C, Ganji SK, DeBerardinis RJ, et al.2-hydroxyglutarate detection by magnetic resonance spectroscopy in IDH-mutated patients with gliomas. Nature medicine. 2012; 18(4): 624-629

43. Longuespee $\mathrm{R}$, Wefers AK, De Vita $\mathrm{E}$, et al.Rapid detection of 2-hydroxyglutarate in frozen sections of IDH mutant tumors by MALDI-TOF mass spectrometry. Acta Neuropathol Commun. 2018; 6(1): 21

44. Kanamori M, Maekawa M, Shibahara I, et al.Rapid detection of mutation in isocitrate dehydrogenase 1 and 2 genes using mass spectrometry. Brain Tumor Pathol. 2018; 35(2): 9096

45. Bralten LB, Kloosterhof NK, Balvers R, et al.IDH1 R132H decreases proliferation of glioma cell lines in vitro and in vivo. Ann Neurol. 2011; 69(3): 455-463

46. Pickard AJ, Sohn AS, Bartenstein TF, et al.Intracerebral Distribution of the Oncometabolite d2-Hydroxyglutarate in Mice Bearing Mutant Isocitrate Dehydrogenase Brain Tumors: Implications for Tumorigenesis. Front Oncol. 2016; 6(211

47. Tateishi K, Wakimoto H, lafrate AJ, et al.Extreme Vulnerability of IDH1 Mutant Cancers to NAD+ Depletion. Cancer Cell. 2015; 28(6): 773-784

48. Fu X, Chin RM, Vergnes L, et al.2-Hydroxyglutarate Inhibits ATP Synthase and mTOR Signaling. Cell Metab. 2015; 22(3): 508-515

49. Zhang Y, Pusch S, Innes J, et al.Mutant IDH Sensitizes Gliomas to Endoplasmic Reticulum Stress and Triggers Apoptosis via miR-183-Mediated Inhibition of Semaphorin 3E. Cancer Res. 2019; 79(19): 4994-5007

50. Rohle D, Popovici-Muller J, Palaskas N, et al.An inhibitor of mutant IDH1 delays growth and promotes differentiation of glioma cells. Science. 2013; 340(6132): 626-630

51. Pusch S, Krausert S, Fischer V, et al.Pan-mutant IDH1 inhibitor BAY 1436032 for effective treatment of IDH1 mutant astrocytoma in vivo. Acta Neuropathol. 2017; 133(4): 629-644

52. Alexandrov LB, Nik-Zainal S, Wedge DC, et al.Signatures of mutational processes in human cancer. Nature. 2013; 500(7463): 415-421 

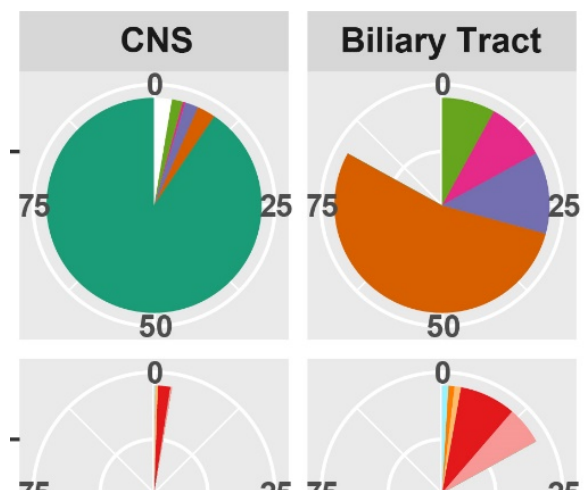

75

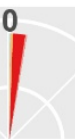

50 $\mathrm{n}=8026$
50 $n=212$

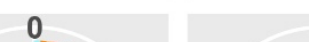

2575

2575

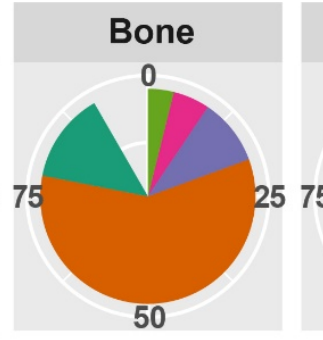

0

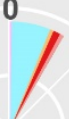

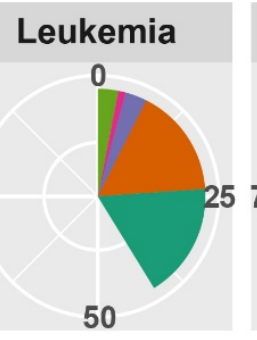

0

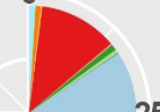

2575
50

$n=361$

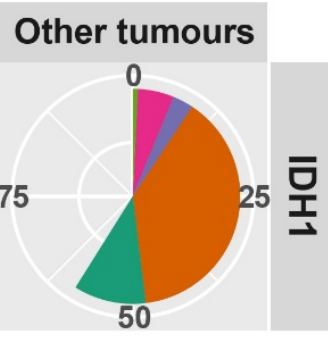

0

2575

50

$\mathrm{n}=2995$
50

$n=129$

\begin{tabular}{|c|c|c|c|}
\hline \multicolumn{4}{|l|}{ IDH2 } \\
\hline R140Q & R140W & R172M & R172T \\
\hline R140G & R172W & R172G & \\
\hline R140L & R172K & R172S & \\
\hline
\end{tabular}

Figure 1: IDH1 and IDH2 hotspot mutation distribution separated by site of origin. IDH1 ${ }^{\mathrm{R} 132 \mathrm{H}}$ mutations are the most predominant mutation in gliomas, IDH2 mutations are most common to haematopoietic tumours. 
bioRxiv preprint doi: https://doi.org/10.1101/2020.12.10.419333; this version posted December 11, 2020. The copyright holder for this preprint (which was not certified by peer review) is the author/funder. All rights reserved. No reuse allowed without permission.

A

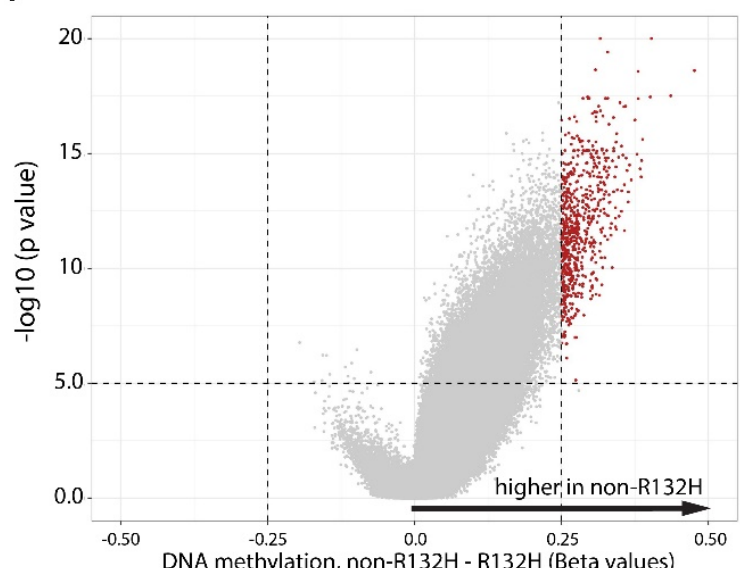

C

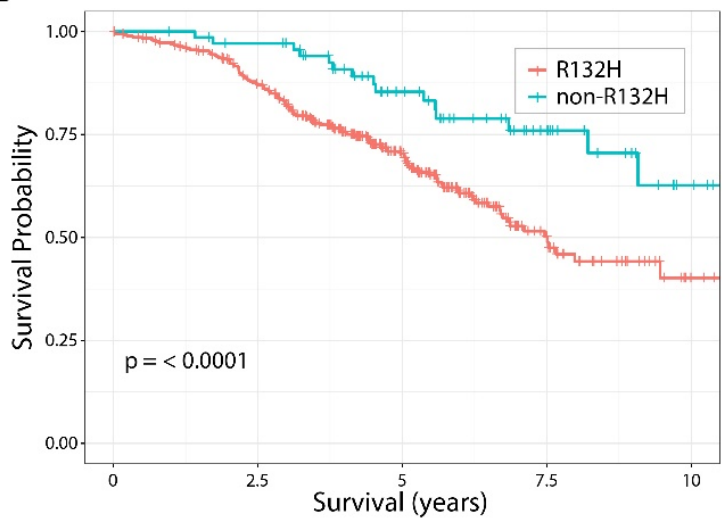

B

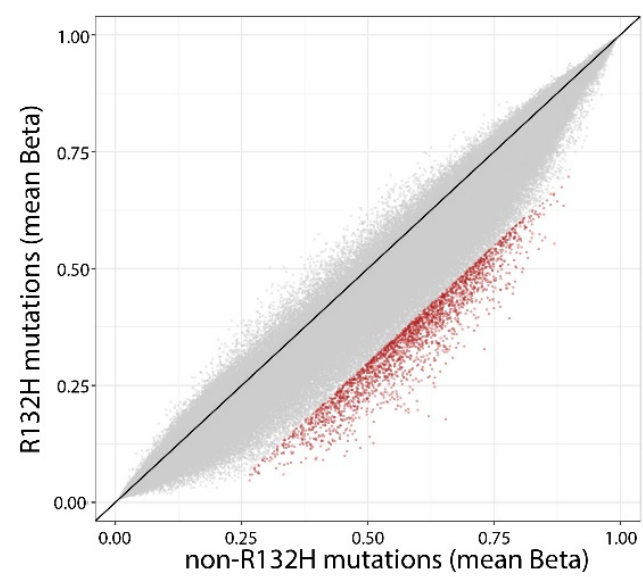

D

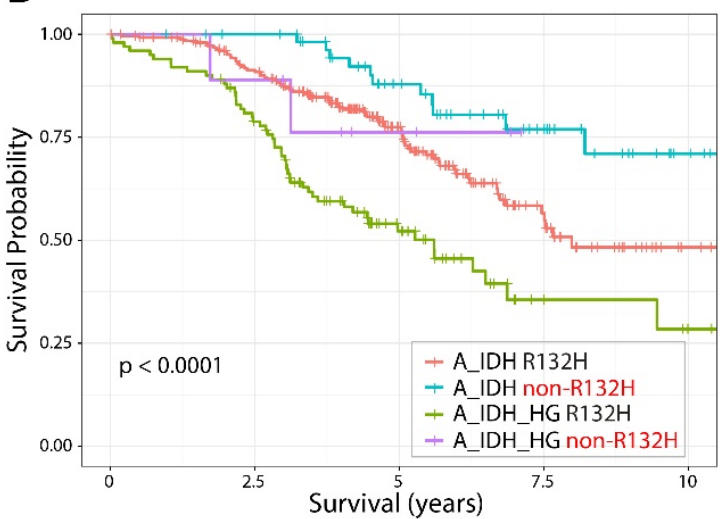

$\mathrm{E}$

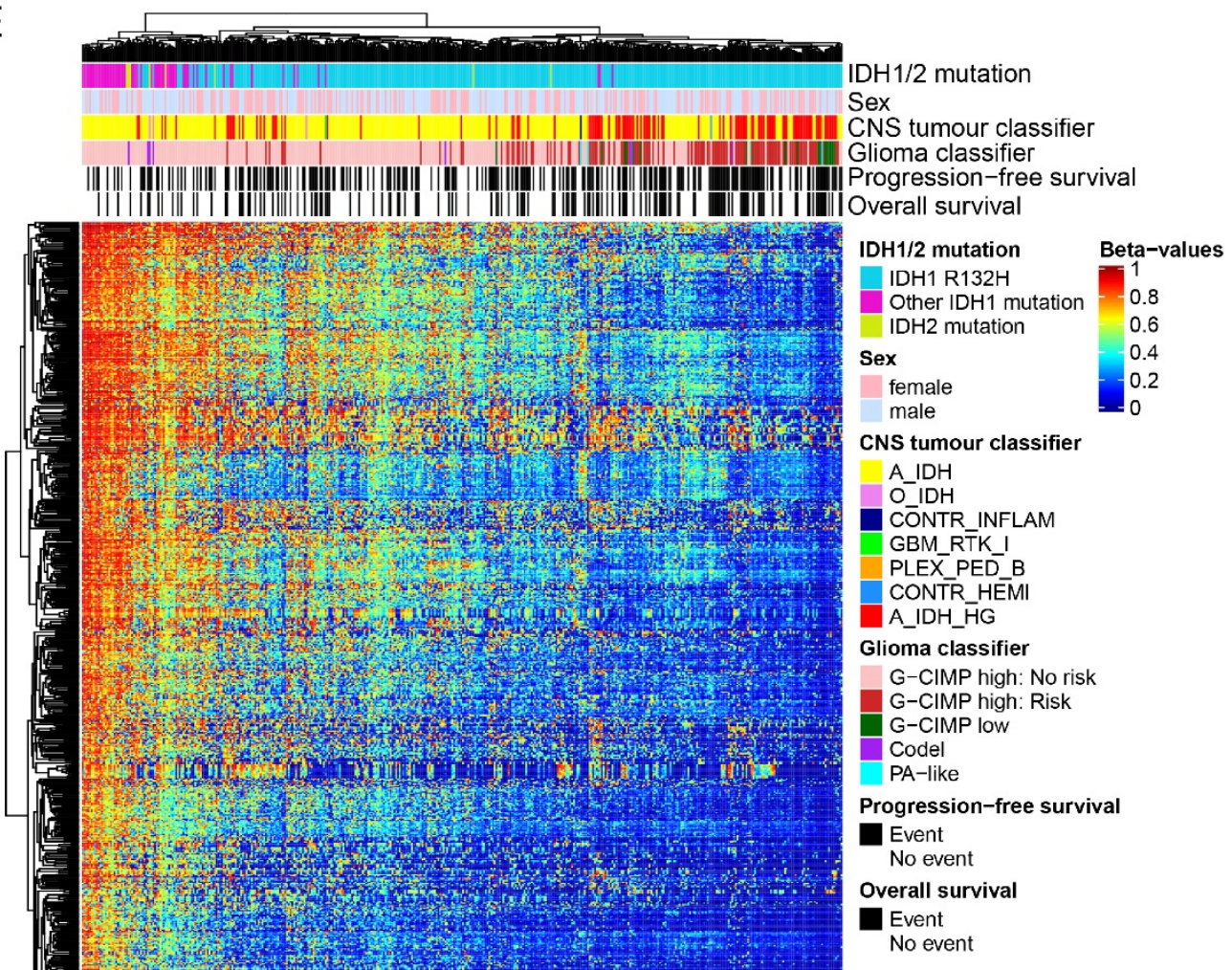


Figure 2: non-R132H mutations are associated with higher DNA methylation levels and improved survival of 1p19q non-codeleted astrocytoma patients included in the CATNON trial. Volcanoplot (A) and $\mathrm{XY}$ plot (B) showing differences in methylation in non- $\mathrm{R} 132 \mathrm{H} \mathrm{v}$. IDH1 ${ }^{\mathrm{R} 132 \mathrm{H}}$ mutated tumours. $\mathrm{C}$ ) patients harbouring non- $\mathrm{R} 132 \mathrm{H}$ mutated tumours have improved outcome, which is independent of methylation class (D). Heatmap of the most differentially methylated probes (red dots in A and B), shows a gradient in methylation levels. Non-R132H mutated tumours cluster at the far left (high methylation), where poor prognostic methylation subtypes (epigenetics subtypes) cluster at the opposite end. 
A

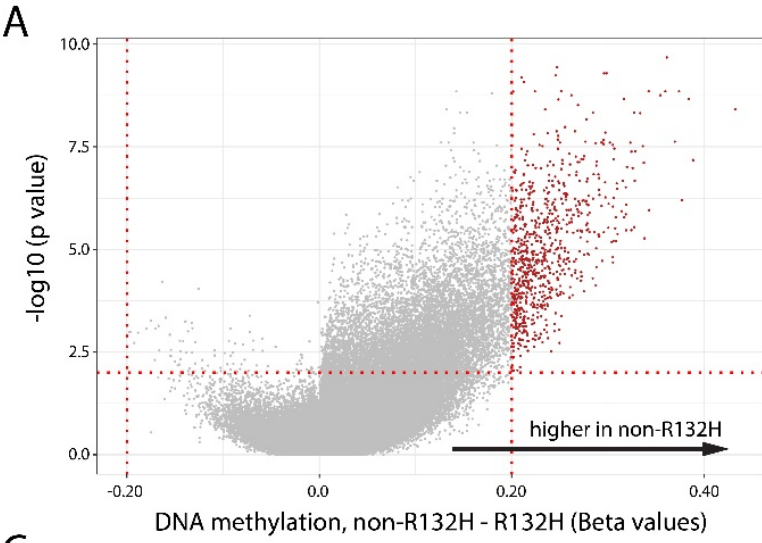

C

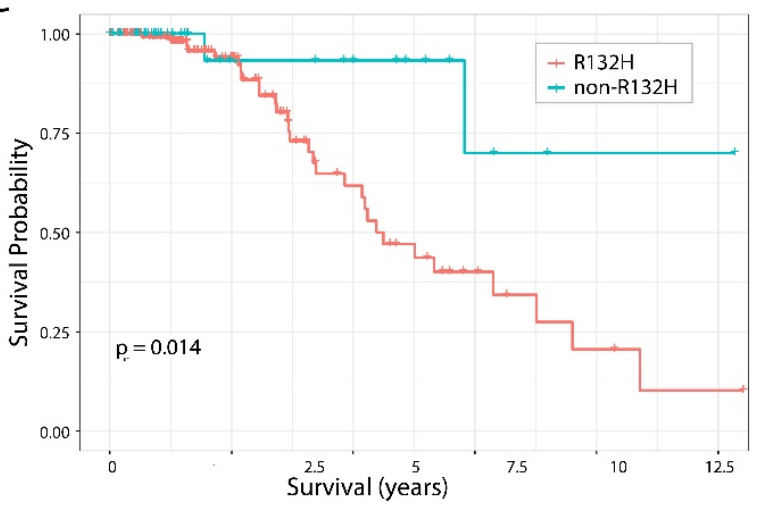

B

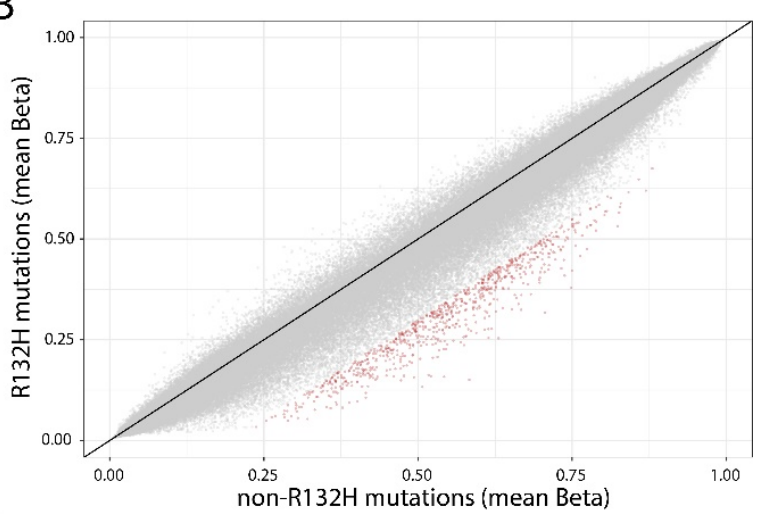

D

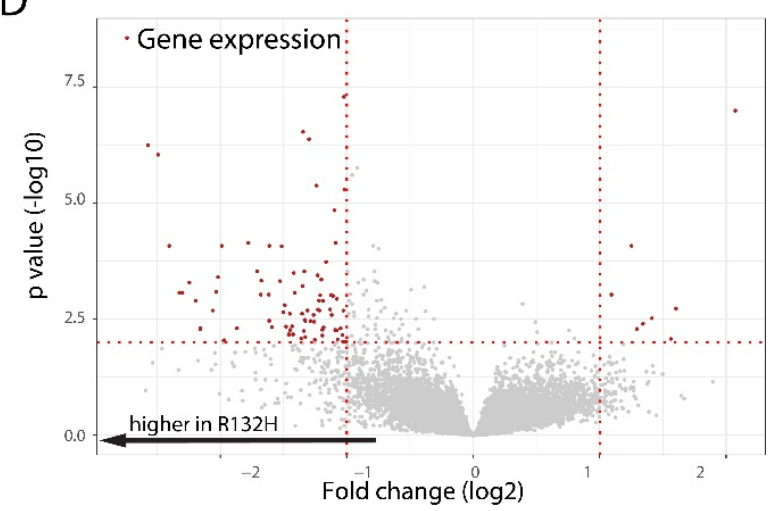

Figure 3: non-R132H mutations are associated with higher DNA methylation levels, lower gene expression and improved survival of 1p19q non-codeleted astrocytoma patients of the TCGA. Volcanoplot (A) and XY plot (B) showing differences in methylation in non-R132H v. IDH1 ${ }^{R 132 H}$ mutated tumours. C) patients harbouring non-R132H mutated tumours have improved outcome. (D) Volcanoplot showing differential expresson of genes between non- $\mathrm{R} 132 \mathrm{H}$ and IDH1 ${ }^{\mathrm{R} 132 \mathrm{H}}$ mutated tumours. Most differentially expressed genes (red dots) have lower expression in non-R132H mutated tumours (see also supplementary table 2). 
A

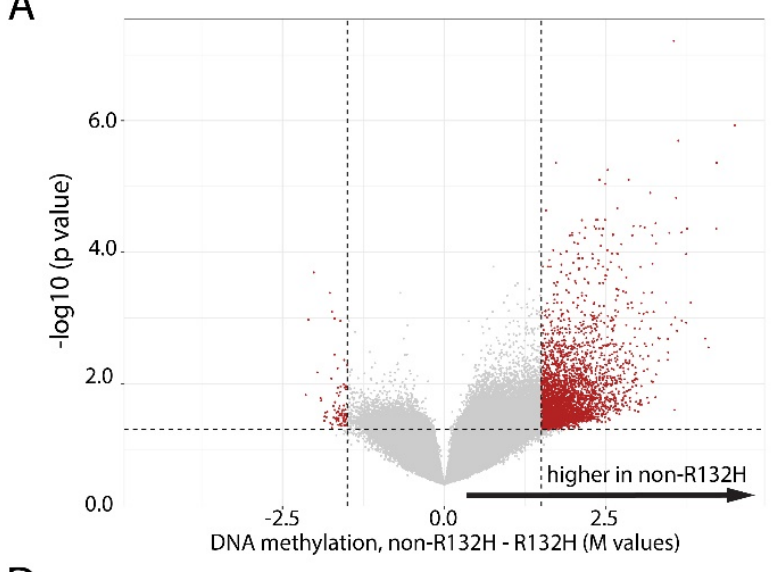

D

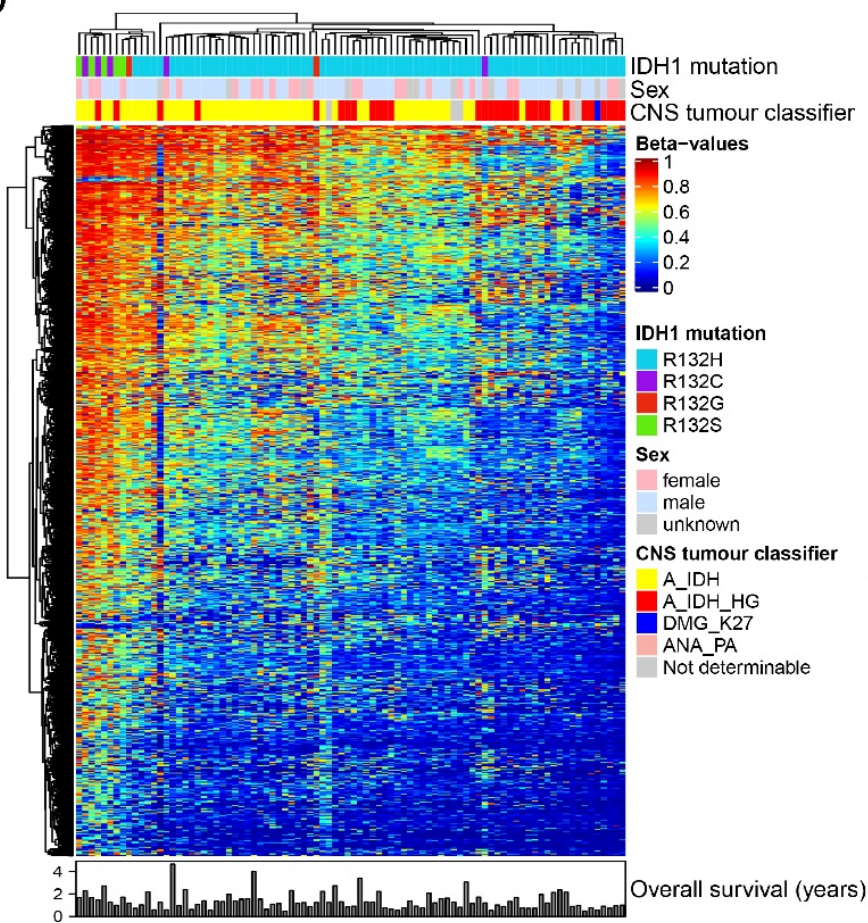

B

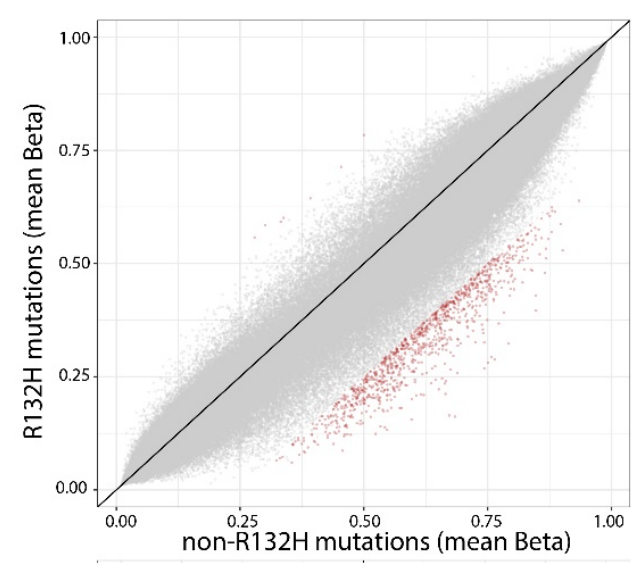

C

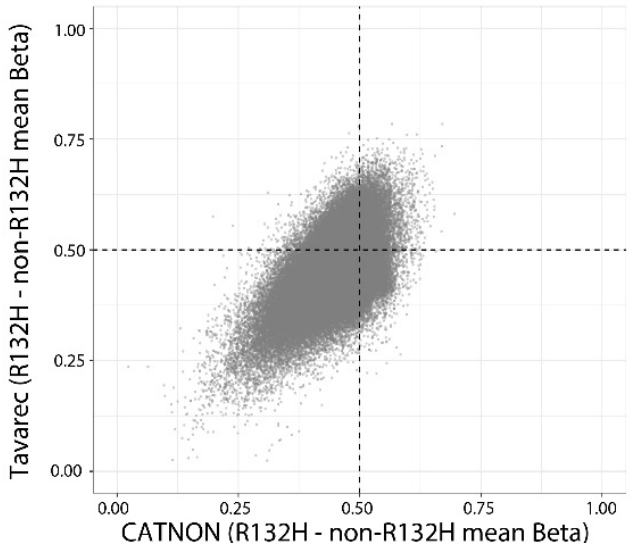

$E$

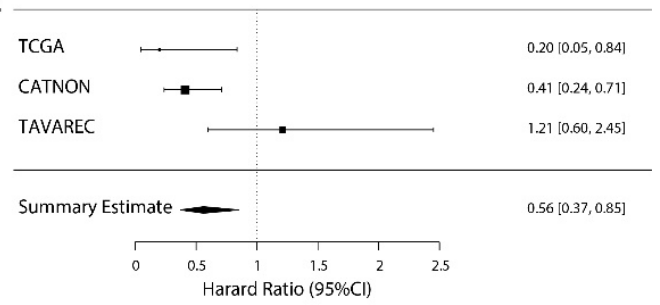

Figure 4: non-R132H mutations are associated with higher DNA methylation levels in 1p19q noncodeleted astrocytoma samples of patients included in the Tavarec trial. Volcanoplot (A) and XY plot (B) showing differences in methylation in non- $\mathrm{R} 132 \mathrm{H}$ v. IDH1 ${ }^{\mathrm{R} 132 \mathrm{H}}$ mutated tumours. C) Differential methylation between non-R132H v. IDH1 ${ }^{\mathrm{R} 132 \mathrm{H}}$ mutated tumours showed a large degree of overlap in CATNON ( $x$ axis) and Tavarec ( $y$ axis) samples. (D) Heatmap of the most differentially methylated probes (red dots in $A$ and $B$ ), shows a gradient in methylation levels. Non-R132H mutated tumours cluster at the far left (high methylation), where poor prognostic methylation subtypes (epigenetics subtypes) cluster at the opposite end. E) Forrest plot showing the summary HR estimate of 1p19q non-codeleted astrocytoma patients harbouring non-R132H v. IDH1 ${ }^{\mathrm{R} 132 \mathrm{H}}$ mutated tumours. 
A

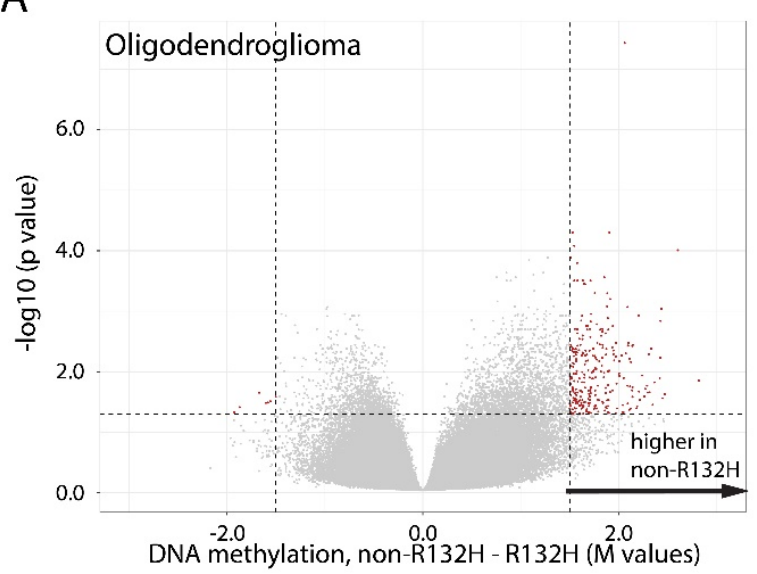

B

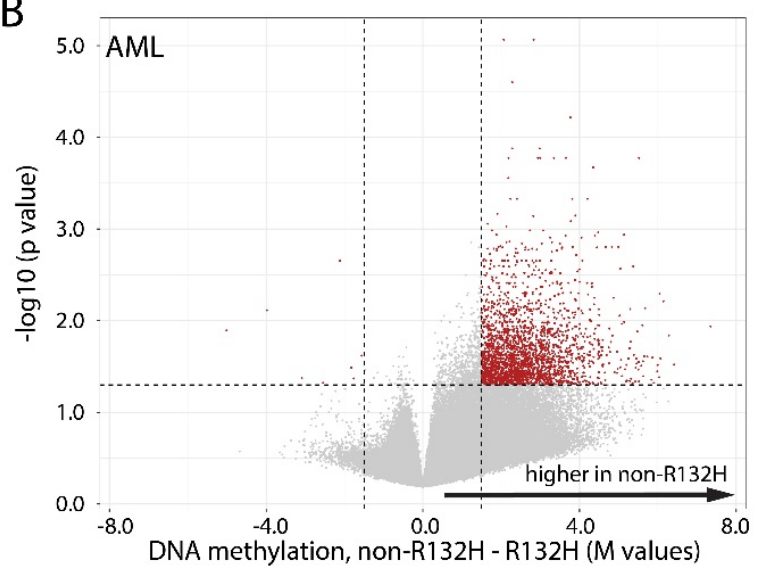

C

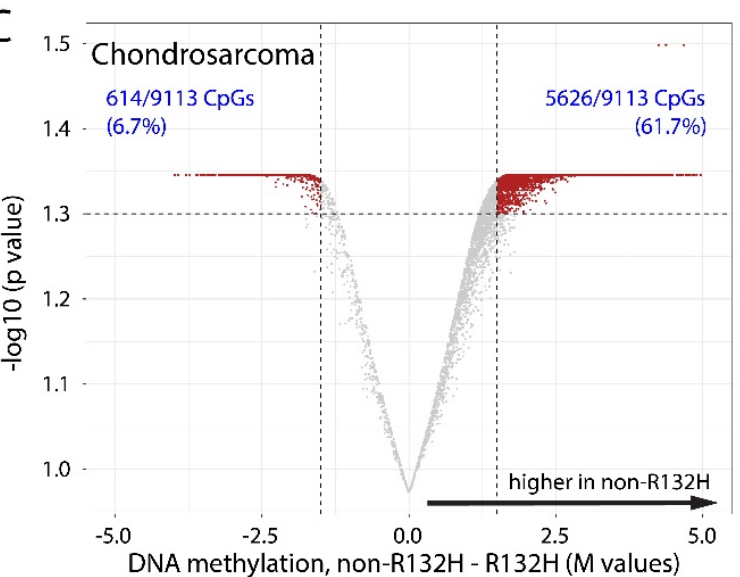

D

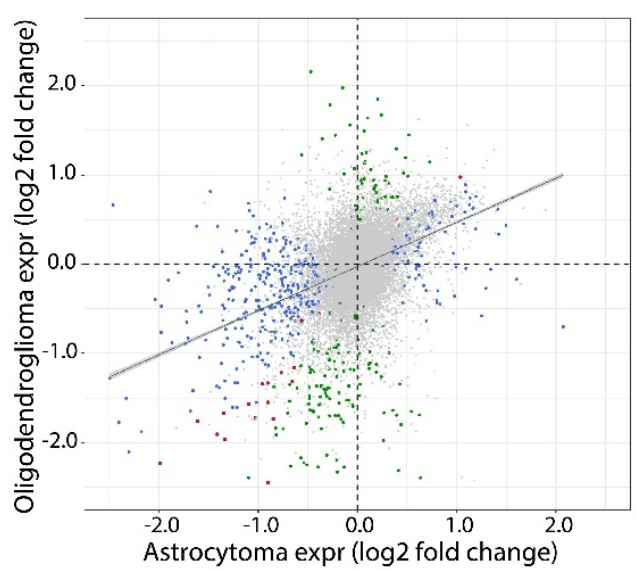

$\mathrm{E}$
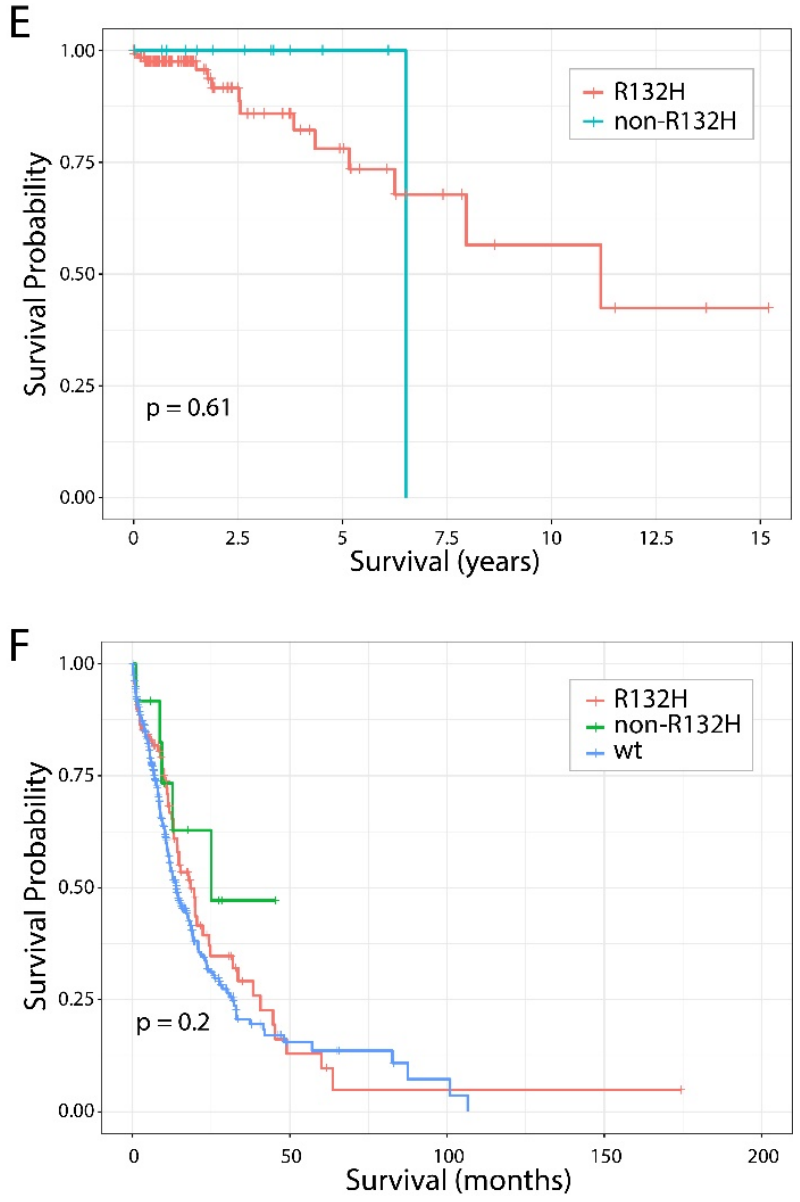

Figure 5: non-R132H mutations are associated with higher DNA methylation levels independent of tumour type. Volcanoplot of 1p19q codeleted oligodendrogliomas (A), AML (B) and chondrosarcomas (C) showing differences in methylation in non- $\mathrm{R} 132 \mathrm{H} \mathrm{v}$. IDH1 ${ }^{\mathrm{R} 132 \mathrm{H}}$ mutated tumours. Red dots depict $\mathrm{CpGs}$ that had a $>0.2$ change in beta value, and were significant $(P<0.01)$ in a Wilcoxon rank test (in $\mathrm{B}$ and $\mathrm{C}$, the $\mathrm{Y}$-axis are $\mathrm{t}$-test $\mathrm{P}$-values for visualization purposes). Although the difference in chondrosarcomas is less than in other tumour types, the majority of significant CpGs was in non-R132H-mutated tumours (e.g. $225 \mathrm{CpG}$ showed a $>0.3$ increase in beta value at $p<0.01$ where only 47 showed a similar decrease). D) Gene expression differences between non$\mathrm{R} 132 \mathrm{H} \mathrm{v}$. IDH1 $1^{\mathrm{R} 132 \mathrm{H}}$ mutated tumours in $1 \mathrm{p} 19 \mathrm{q}$ non-codeleted astrocytomas ( $\mathrm{x}$-axis) and $1 \mathrm{p} 19 \mathrm{q}$ codeleted oligodendrogliomas ( $y$-axis) shows a large degree of overlap. Blue, green and red dots 
depict genes significantly differentially expressed in astrocytomas, oligodendrogliomas or both respectively (see also supplementary table 2 and 3). E). Survival of 1p19q codeleted oligodendroglioma patients present in the TCGA database harbouring non-R132H v. IDH1 ${ }^{\mathrm{R} 132 \mathrm{H}}$ mutated tumours. There were too few events evaluate survival differences per mutation type. F) mutation type-specific survival differences in AML. 
Table 1. Multivariable model

\begin{tabular}{|c|c|c|c|c|c|}
\hline \multirow[b]{2}{*}{ IDH mutation type } & \multirow[b]{2}{*}{ non-R132H v. R132H } & \multirow{2}{*}{$\begin{array}{c}\text { HR } \\
0.486\end{array}$} & \multicolumn{2}{|c|}{$95 \% \mathrm{Cl}$} & \multirow{2}{*}{$\begin{array}{c}\text { p value } \\
0.012\end{array}$} \\
\hline & & & 0.278 & 0.852 & \\
\hline Sex & Male v. Female & 1.465 & 1.033 & 2.076 & 0.032 \\
\hline \multirow[t]{3}{*}{ Treatment } & RT->TMZ v. RT & 0.410 & 0.257 & 0.653 & 0.000 \\
\hline & TMZ/RT v. RT & 0.802 & 0.520 & 1.237 & 0.319 \\
\hline & TMZ/RT->TMZ v. RT & 0.385 & 0.231 & 0.639 & 0.000 \\
\hline \multirow[t]{2}{*}{ Age } & $40-60$ v. $<40$ years & 1.121 & 0.656 & 1.914 & 0.677 \\
\hline & $>60 \mathrm{v} .<40$ years & 3.824 & 1.812 & 8.069 & 0.000 \\
\hline \multirow[t]{2}{*}{ Performance score } & 1 v. 0 & 1.404 & 0.991 & 1.990 & 0.056 \\
\hline & 2 v. 0 & 2.282 & 0.704 & 7.401 & 0.169 \\
\hline $\begin{array}{l}\text { MGMT promoter } \\
\text { methylation }\end{array}$ & UM v. M & 1.001 & 0.640 & 1.567 & 0.996 \\
\hline Corticosteroid use & Yes v. No & 1.099 & 0.742 & 1.627 & 0.639 \\
\hline \multirow[t]{3}{*}{ Methylation subtype } & A_IDH_HG V.A_IDH & 2.650 & 1.828 & 3.842 & 0.000 \\
\hline & O_IDH v. A_IDH & 0.362 & 0.083 & 1.584 & 0.177 \\
\hline & other v. A IDH & 10.763 & 3.410 & 33.970 & 0.000 \\
\hline
\end{tabular}



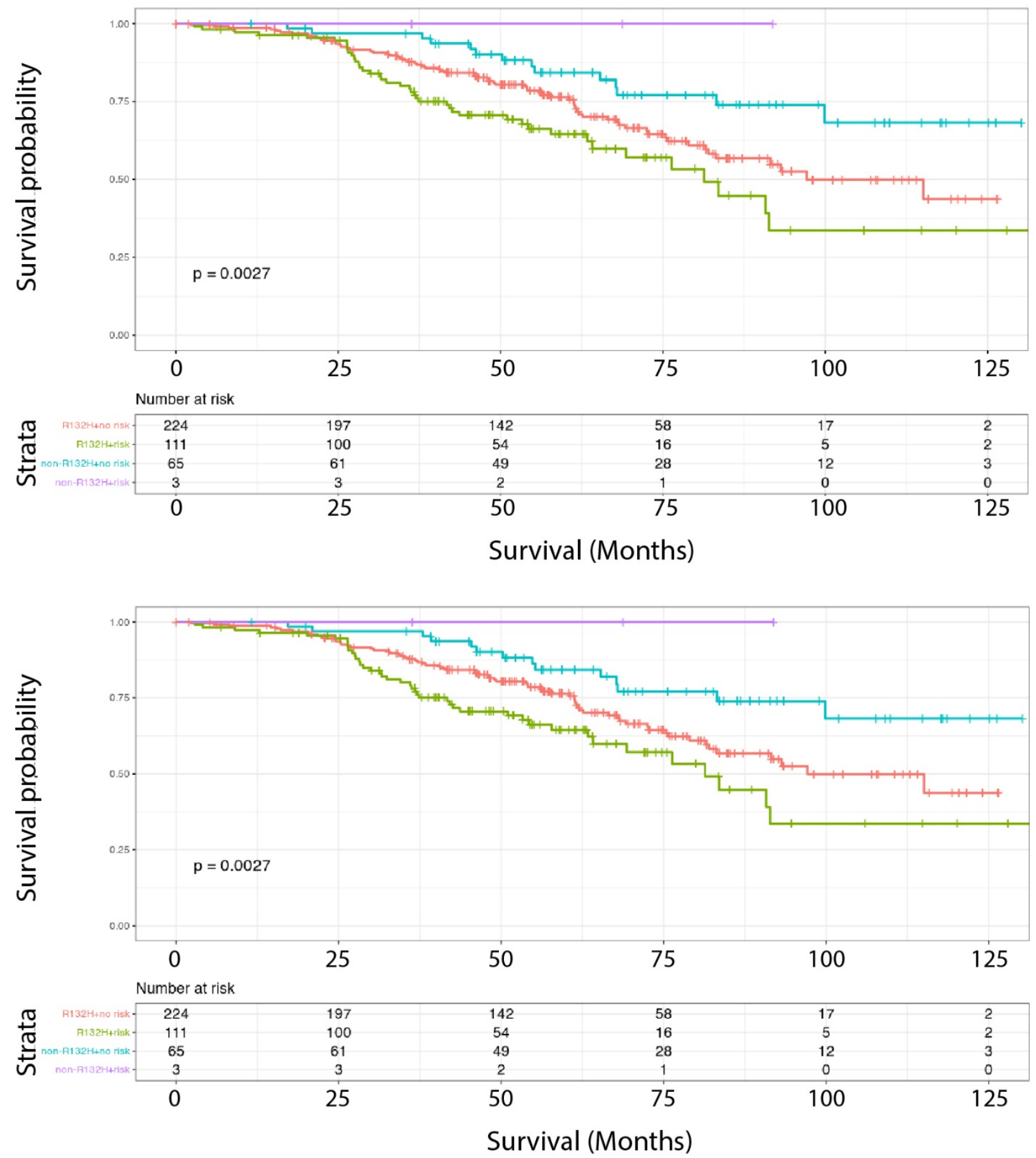

Supplementary figure 1: non-R132H mutations are associated with improved survival of 1p19q noncodeleted astrocytoma patients included in the CATNON trial independent of methylation class. Survival of patients harbouring non- $\mathrm{R} 132 \mathrm{H}$ or $\mathrm{IDH} 1^{\mathrm{R} 132 \mathrm{H}}$ mutated tumours stratified by methylation class as defined by the TCGA (top) or risk to G-CIMP-low progression (bottom). As can be seen, patients harbouring non- $\mathrm{R} 132 \mathrm{H}$ mutated tumours have improved outcome, independent of methylation class. 
A

Diseases and Disorders
Name
Connective Tissue Disorders

B

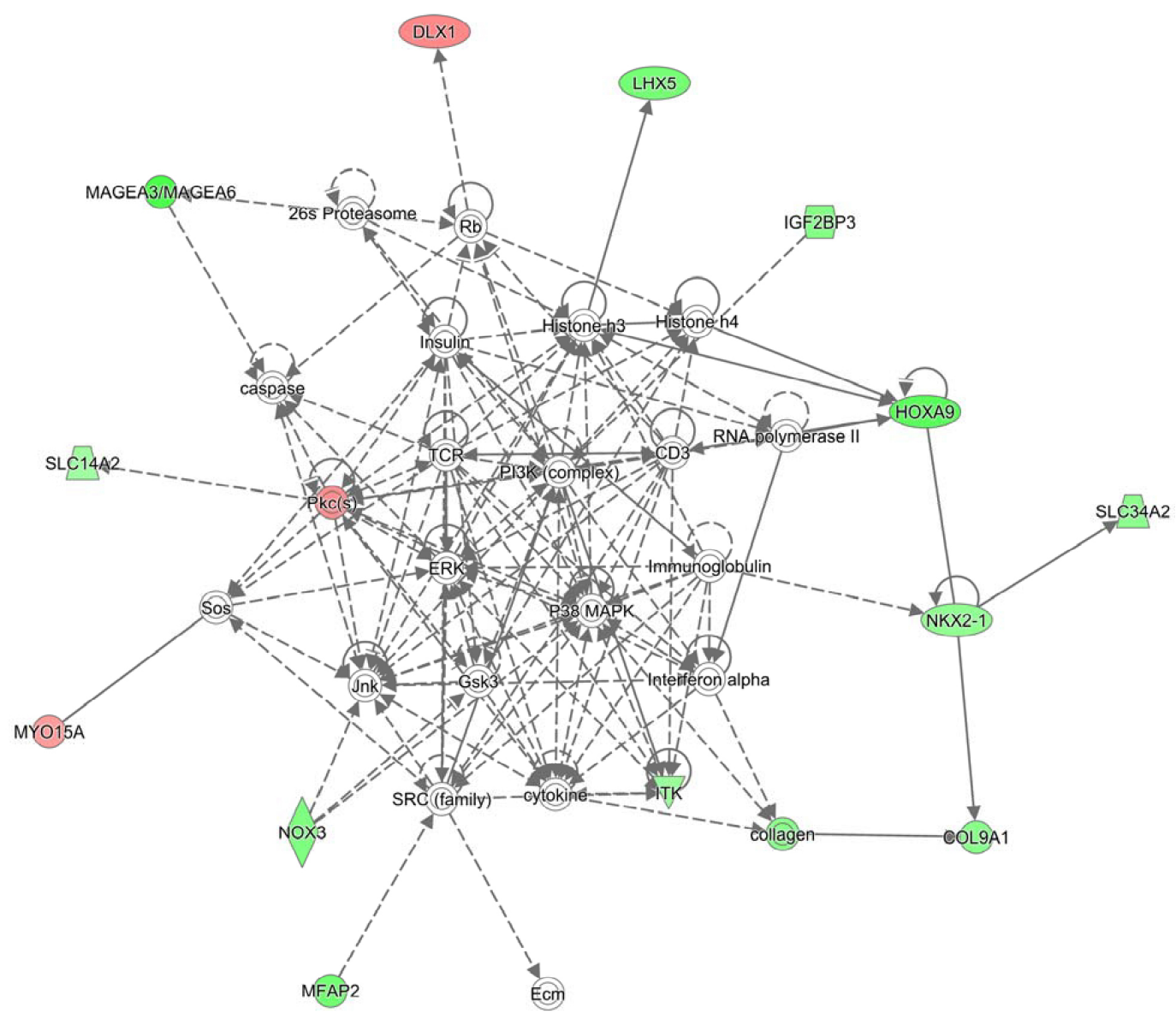

Supplementary figure 2: Pathway analysis of genes differentially expressed between non-R132H and $\mathrm{IDH} 1^{\mathrm{R} 132 \mathrm{H}}$ mutated tumours. A) top diseases and disorders, molecular and cellular functions and physiological system development and function identified by pathway analysis. B) graphical representation of the top cancer pathway. 
Supplementary table 1

\begin{tabular}{lrrrrc}
\hline & & HR & \multicolumn{2}{c}{ 95\% Cl } & p value \\
\hline IDH mutation type & non-R132H v. R132H & 0.378 & 0.217 & 0.659 & 0.0006 \\
\hline Sex & Male v. Female & 1.377 & 0.978 & 1.939 & 0.067 \\
\hline Treatment & RT->TMZ v. RT & 0.485 & 0.307 & 0.768 & 0.002 \\
\hline & TMZ/RT v. RT & 0.734 & 0.479 & 1.124 & 0.154 \\
\hline Age & TMZ/RT->TMZ v. RT & 0.432 & 0.266 & 0.703 & 0.0007 \\
\hline Performance score & 40-60 v. <40 years & 1.021 & 0.598 & 1.744 & 0.94 \\
\hline & $>60$ v. <40 years & 2.413 & 1.188 & 4.903 & 0.015 \\
\hline MGMT promoter & 1 v. 0 & 1.455 & 1.030 & 2.055 & 0.033 \\
methylation & 2 v. 0 & 1.732 & 0.540 & 5.563 & 0.36 \\
Corticosteroid use & & & & & \\
\hline & UM v. M & 1.092 & 0.715 & 1.668 & 0.68 \\
\hline
\end{tabular}


Supplementary table 2

\begin{tabular}{lrrrrr}
\hline & & HR & \multicolumn{2}{c}{$95 \%$ Cl } & p value \\
\hline IDH mutation type & non-R132H v. R132H & 0.429 & 0.245 & 0.751 & 0.003 \\
\hline Sex & Male v. Female & 1.393 & 0.985 & 1.971 & 0.061 \\
Treatment & RT->TMZ v. RT & 0.443 & 0.280 & 0.703 & 0.001 \\
\hline & TMZ/RT v. RT & 0.744 & 0.484 & 1.144 & 0.178 \\
\hline Age & TMZ/RT->TMZ v. RT & 0.441 & 0.267 & 0.728 & 0.001 \\
\hline Performance score & 40-60 v. <40 years & 1.167 & 0.679 & 2.004 & 0.577 \\
\hline & $>60$ v. < 40 years & 3.082 & 1.483 & 6.407 & 0.003 \\
\hline MGMT promoter & 1 v. 0 & 1.501 & 1.057 & 2.130 & 0.023 \\
methylation & 2 v. 0 & 1.989 & 0.617 & 6.410 & 0.250 \\
\hline Corticosteroid use & & & & & \\
Methylation subtype & UM v. M & 0.970 & 0.627 & 1.500 & 0.891 \\
\hline & Yes v. No & 1.271 & 0.861 & 1.877 & 0.228 \\
\hline & G-CIMP low v G-CIMP high & 4.072 & 2.231 & 7.430 & 0.000 \\
\hline
\end{tabular}


Supplementary table 3

\begin{tabular}{|lr|}
\hline Gene.name & log2 FoldChange \\
\hline AJ011932.1 & -2.737589267 \\
PCDHGB4 & -2.571945205 \\
CEACAM5 & -2.5341973 \\
SHOX2 & -2.492427446 \\
KRT13 & -2.460839239 \\
AC104051.2 & -2.403250008 \\
IGHV1-18 & -2.330831346 \\
HOXA5 & -2.323982392 \\
LINC01956 & -2.300130233 \\
LINC02513 & -2.24479318 \\
NTS & -2.194539237 \\
SIX6 & -2.175101096 \\
EN1 & -2.158765071 \\
HOXA7 & -2.157135213 \\
MAGEA6 & -2.071106151 \\
HOXA10 & -2.059261084 \\
IL21-AS1 & -2.042870083 \\
IBSP & -2.036361159 \\
SCGB3A2 & -2.030888599 \\
CCDC198 & -2.018895459 \\
MTCYBP18 & -1.988541182 \\
HOXD9 & -1.97664222 \\
H1-9P & -1.974360534 \\
LINC01993 & -1.969448233 \\
AC015909.3 & -1.905007912 \\
KRT16 & -1.891557269 \\
HOXA9 & -1.883361185 \\
TBX5 & -1.867429903 \\
H19 & -1.801177989 \\
LRRC18 & -1.777074293 \\
DLK1 & -1.727130873 \\
IDO1 & -1.72137244 \\
CNIH3-AS1 & -1.719623402 \\
AC096669.1 & -1.707462577 \\
SCNN1B & -1.680229048 \\
AC068308.1 & -1.675592245 \\
PLEKHS1 & -1.656709761 \\
DAO & -1.643293356 \\
MFAP2 & -1.616778551 \\
HAGLROS & -1.612619442 \\
LINC1235 & -1.611484946 \\
\hline
\end{tabular}




$\begin{array}{|lr|}\text { TBX5-AS1 } & -1.597762594 \\ \text { CHI3L1 } & -1.591438123 \\ \text { LHX5 } & -1.575761551 \\ \text { MIR4527HG } & -1.52646164 \\ \text { LINC01485 } & -1.515218265 \\ \text { AC062021.1 } & -1.501396095 \\ \text { TRIM71 } & -1.490465977 \\ \text { SLC17A8 } & -1.479718763 \\ \text { AC253536.4 } & -1.460186616 \\ \text { LINC01571 } & -1.454158719 \\ \text { LCE1E } & -1.450018917 \\ \text { NOX3 } & -1.44740241 \\ \text { AC104574.2 } & -1.432576878 \\ \text { IL13RA2 } & -1.426872513 \\ \text { C3Orf22 } & -1.426816188 \\ \text { C2Orf91 } & -1.424551675 \\ \text { AL390755.2 } & -1.417799432 \\ \text { LINC01579 } & -1.410814502 \\ \text { PCAT4 } & -1.408801892 \\ \text { IGF2-AS } & -1.407277847 \\ \text { IGF2BP3 } & -1.394810745 \\ \text { AC008080.4 } & -1.388244005 \\ \text { ASB11 } & -1.374324083 \\ \text { AL158058.1 } & -1.37079861 \\ \text { AC084864.1 } & -1.360024733 \\ \text { SPOCD1 } & -1.356355284 \\ \text { HAMP } & -1.353158198 \\ \text { TGFB2 } & -1.350160759 \\ \text { TRPC7 } & -1.349144827 \\ \text { APOH } & -1.34872969 \\ \text { DLGAP1-AS5 } & -1.345754514 \\ \text { BINC01387 } & -1.2587961951209\end{array}$




\begin{tabular}{|lr|} 
AC008760.2 & -1.257935042 \\
ASB5 & -1.256795604 \\
PCDHGA3 & -1.252469346 \\
FGFBP2 & -1.250388105 \\
CXCL10 & -1.250319136 \\
SLPI & -1.239113683 \\
LINC00606 & -1.230027579 \\
IL21R & -1.229097284 \\
TFAP2A & -1.227993409 \\
IFI6 & -1.218666285 \\
S100A3 & -1.217530644 \\
ARHGAP36 & -1.214660604 \\
AL049839.2 & -1.214006748 \\
NA & -1.209976594 \\
PIRT & -1.206189984 \\
VGF & -1.202116275 \\
AC126773.4 & -1.200656398 \\
TRPM8 & -1.198024209 \\
SLCO4A1-AS1 & -1.192055585 \\
SLC18A1 & -1.191695755 \\
RPS3AP5 & -1.18708919 \\
AC073389.2 & -1.183287408 \\
AP005202.1 & -1.182697026 \\
TREM1 & -1.176000574 \\
ITK & -1.172545553 \\
ULBP1 & -1.166387637 \\
HNRNPKP3 & -1.162965555 \\
AC107419.1 & -1.162344351 \\
ARSF & -1.150883317 \\
LINC02574 & -1.150231164 \\
LCE1D & -1.143358674 \\
AC112493.1 & -1.14299355 \\
ABCA13 & -1.131583881 \\
PTX3 & -1.124334869 \\
C10orf105 & -1.121615634 \\
LINC02282 & -1.120792665 \\
GRHL3-AS1 & -1.119249705 \\
AC002546.1 & -1.119126233 \\
TIMP4 & -1.107649912 \\
FAM151A & -1.097568155 \\
NR1H4 & -1.096213209 \\
MC04899.2 & -1.091653154 \\
-1.087380276 \\
\hline INSM1 & -1.086795726 \\
\hline
\end{tabular}




\begin{tabular}{|c|c|}
\hline ADAMTS7P4 & -1.075366136 \\
\hline AC027281.2 & -1.071532654 \\
\hline ADIG & -1.070317119 \\
\hline LINC01224 & -1.070240332 \\
\hline LINC02029 & -1.069804734 \\
\hline NA & -1.067618019 \\
\hline TMSB15A & -1.067419295 \\
\hline GNLY & -1.063935711 \\
\hline PCDHA7 & -1.059616824 \\
\hline CFAP77 & -1.048266211 \\
\hline CDC14C & -1.040485693 \\
\hline LINC01349 & -1.03912138 \\
\hline AC023421.1 & -1.034292301 \\
\hline TNFSF13B & -1.029345357 \\
\hline THEM7P & -1.027307556 \\
\hline MT1F & -1.02610821 \\
\hline LINC02777 & -1.021269904 \\
\hline VEPH1 & -1.018627595 \\
\hline EYA1 & -1.018248945 \\
\hline USP30-AS1 & -1.011199972 \\
\hline C21orf62 & -1.003904261 \\
\hline MY015A & 1.002369696 \\
\hline REM1 & 1.036824656 \\
\hline SLCO4C1 & 1.068178932 \\
\hline AC103681.2 & 1.075356234 \\
\hline GRM2 & 1.080043134 \\
\hline CALML3-AS1 & 1.085922855 \\
\hline OTOF & 1.090196171 \\
\hline SGCG & 1.092779196 \\
\hline TNIP3 & 1.104033991 \\
\hline PRKCG & 1.129143448 \\
\hline GNG13 & 1.135341651 \\
\hline FBXO40 & 1.163078138 \\
\hline TPO & 1.188794917 \\
\hline DLX1 & 1.190730282 \\
\hline CLEC4G & 1.194118952 \\
\hline PCDHGB3 & 1.251510045 \\
\hline S100A7 & 1.294257769 \\
\hline МTCO3P12 & 1.341898853 \\
\hline SLC22A9 & 1.369452854 \\
\hline PRND & 1.413607686 \\
\hline PRTN3 & 1.419613663 \\
\hline KLK7 & 1.424761311 \\
\hline AC140125.2 & 1.497638207 \\
\hline CLEC4GP1 & 1.562749558 \\
\hline SLC38A4 & 1.603508363 \\
\hline NPIPB13 & 2.07239819 \\
\hline
\end{tabular}


Supplementary table 4

\begin{tabular}{|lr|}
\hline Gene.name & log2FoldChange \\
\hline MTRNR2L1 & -5.520724037 \\
LINC01055 & -4.380363929 \\
PITX1 & -3.992410842 \\
CCDC198 & -3.91584956 \\
TFAP2B & -3.824382791 \\
DAO & -3.704166761 \\
AC068308.1 & -3.243847134 \\
CNN2P8 & -3.148696973 \\
AC023421.1 & -2.916224137 \\
LINC01485 & -2.808094538 \\
SLC14A2 & -2.798813886 \\
STON1- & \\
GTF2A1L & -2.725619928 \\
CCL1 & -2.706869245 \\
EN1 & -2.62447316 \\
ISL2 & -2.597031297 \\
CHIT1 & -2.530243103 \\
IL13RA2 & -2.505016251 \\
ENOX1-AS2 & -2.447615266 \\
AC022498.1 & -2.390691554 \\
CHRM5 & -2.390294807 \\
PCDHGB1 & -2.328605085 \\
PCDHGB6 & -2.312015563 \\
SLC14A1 & -2.270870574 \\
NMUR2 & -2.270733359 \\
SLC47A2 & -2.262412923 \\
AL603840.1 & -2.248180985 \\
MTCYBP18 & -2.224655459 \\
KIF6 & -2.223589491 \\
TFCP2L1 & -2.193455866 \\
LINC02308 & -2.167770915 \\
AL033519.1 & -2.136495258 \\
AC091151.1 & -1.975602204 \\
AC005999.1 & -1.965555734 \\
LINC01894 & -1.912781222 \\
LINC01579 & -1.9039876 \\
AL355916.2 & -1.84043909 \\
SFRP2 & -1.839939629 \\
GSX2 & -1.835719986 \\
CCL4L2 & -1.794607717 \\
NA 1.77316 .3 & -1.736707567
\end{tabular}




\begin{tabular}{|c|c|}
\hline AL161935.1 & -1.732663246 \\
\hline TNFSF13B & -1.723565612 \\
\hline RN7SKP23 & -1.713341854 \\
\hline AL355482.1 & -1.708920378 \\
\hline TIGIT & -1.697341592 \\
\hline HIRAP1 & -1.695118366 \\
\hline LINC00994 & -1.693595145 \\
\hline CCL4 & -1.689420884 \\
\hline CCL3L1 & -1.685923314 \\
\hline DLGAP1-AS5 & -1.665873392 \\
\hline SNORC & -1.6651562 \\
\hline IL1B & -1.661839939 \\
\hline THORLNC & -1.652046554 \\
\hline CCL3 & -1.647463936 \\
\hline AC092040.2 & -1.643428448 \\
\hline TNFSF18 & -1.635271455 \\
\hline AC139491.2 & -1.630242068 \\
\hline AC068790.1 & -1.594647512 \\
\hline PGM5P4 & -1.588087948 \\
\hline SALL4 & -1.576421413 \\
\hline LPL & -1.574161491 \\
\hline USH1C & -1.56772355 \\
\hline AC092112.1 & -1.565593909 \\
\hline FAM151A & -1.564868904 \\
\hline AC091435.2 & -1.556627129 \\
\hline FAM181A-AS1 & -1.546233218 \\
\hline AC004485.1 & -1.533405325 \\
\hline Z84468.1 & -1.522085163 \\
\hline ССT7P2 & -1.521992916 \\
\hline REELD1 & -1.507029939 \\
\hline AP003472.1 & -1.501948058 \\
\hline AP000424.1 & -1.486411807 \\
\hline AL355974.2 & -1.477589802 \\
\hline CALN1 & -1.471320426 \\
\hline GFAP & -1.469268554 \\
\hline LINC01736 & -1.443494141 \\
\hline TRDN & -1.437372297 \\
\hline AC005162.2 & -1.400400857 \\
\hline TLR4 & -1.399146112 \\
\hline SLC11A1 & -1.389398943 \\
\hline AP004782.1 & -1.386916969 \\
\hline AL390755.1 & -1.382538868 \\
\hline AL391845.2 & -1.373598494 \\
\hline BTC & -1.371751893 \\
\hline AC084880.1 & -1.366963829 \\
\hline AC084880.3 & -1.363921455 \\
\hline LINC01117 & -1.361051862 \\
\hline
\end{tabular}




$\begin{array}{|lr|}\text { ACKR4 } & -1.349531264 \\ \text { FAM184B } & -1.343255695 \\ \text { ACOT11 } & -1.34158337 \\ \text { CH25H } & -1.340510059 \\ \text { MIR3151 } & -1.331716185 \\ \text { LINC01132 } & -1.312126547 \\ \text { AC093305.1 } & -1.302303524 \\ \text { AL035665.1 } & -1.29310018 \\ \text { LINC01933 } & -1.260115378 \\ \text { LINC01480 } & -1.257478371 \\ \text { SLC35E1P1 } & -1.250371519 \\ \text { TEKT3 } & -1.216363248 \\ \text { TMEM72 } & -1.210581484 \\ \text { ADGRE4P } & -1.209793588 \\ \text { CFAP300 } & -1.200305634 \\ \text { HOGA1 } & -1.198967863 \\ \text { GREB1L } & -1.188824146 \\ \text { LINC01094 } & -1.181797216 \\ \text { S100Z } & -1.177196503 \\ \text { WARS2-IT1 } & -1.176083234 \\ \text { PCBP3-AS1 } & -1.175294791 \\ \text { ELN-AS1 } & -1.169291966 \\ \text { LINC01354 } & -1.154376228 \\ \text { TPRG1-AS1 } & -1.151270415 \\ \text { LINC00877 } & -1.139144855 \\ \text { L3MBTL4-AS1 } & -1.12221505 \\ \text { AC093627.7 } & -1.120734298 \\ \text { LINC02145 } & -1.106081339 \\ \text { AL157823.2 } & -1.098547658 \\ \text { RHBDL3 } & -1.09053745 \\ \text { GYG2 } & -1.075122004 \\ \text { LRRC37A7P } & -1.070713931 \\ \text { KCNJ16 } & -1.024858397 \\ \text { CAVIN3 } & 1.009076484 \\ \text { LINC02761 } & 1.018693732 \\ \text { CSAG1 } & 1.059398456 \\ \text { ADAMTSL5 } & 1.069855548 \\ \text { SPOX4I2 } & 1.12645928 \\ \text { HPGD } & 1.143058008 \\ \text { FGF18 } & 1.149908695 \\ \text { PLEKHG4 } & 1.2361497534 \\ \text { MYL9 } & \\ \text { TFI } & \end{array}$


bioRxiv preprint doi: https://doi.org/10.1101/2020.12.10.419333; this version posted December 11 , 2020. The copyright holder for this preprint (which was not certified by peer review) is the author/funder. All rights reserved. No reuse allowed without permission.

\begin{tabular}{|lr|} 
AL109615.3 & 1.446914523 \\
FMO1 & 1.492060237 \\
CNN1 & 1.558405106 \\
GJA5 & 1.635759646 \\
SV2C & 1.67050452 \\
MYOCD & 1.781451983 \\
DES & 1.845422778 \\
LRRC36 & 1.969650897 \\
MYH11 & 2.157843483 \\
PCDHGA6 & 2.7791885 \\
SLC22A8 & 2.917933903 \\
\hline
\end{tabular}

